\title{
CoREST Complex-Selective Histone Deacetylase Inhibitors Show Prosynaptic Effects and an Improved Safety Profile To Enable Treatment of Synaptopathies
}

\author{
Nathan O. Fuller, Antonella Pirone, Berkley A. Lynch, Michael C. Hewitt, Maria S. Quinton, ${ }^{\dagger}$
} Timothy D. McKee, ${ }^{\ddagger}$ and Magnus Ivarsson*

Rodin Therapeutics, 300 Technology Square, Cambridge, Massachusetts 02139, United States

Supporting Information

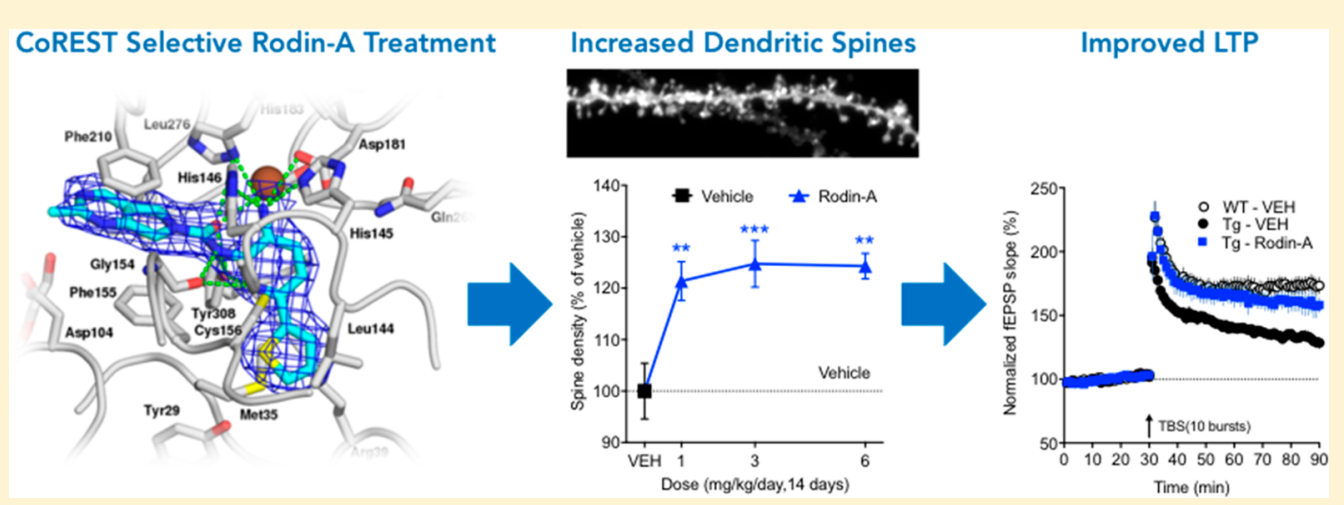

ABSTRACT: Synaptic dysfunction is a pathological feature in many neurodegenerative disorders, including Alzheimer's disease, and synaptic loss correlates closely with cognitive decline. Histone deacetylases (HDACs) are involved in chromatin remodeling and gene expression and have been shown to regulate synaptogenesis and synaptic plasticity, thus providing an attractive drug discovery target for promoting synaptic growth and function. To date, HDAC inhibitor compounds with prosynaptic effects are plagued by known HDAC dose-limiting hematological toxicities, precluding their application to treating chronic neurologic conditions. We have identified a series of novel HDAC inhibitor compounds that selectively inhibit the HDAC-co-repressor of repressor element-1 silencing transcription factor (CoREST) complex while minimizing hematological side effects. HDAC1 and HDAC2 associate with multiple co-repressor complexes including CoREST, which regulates neuronal gene expression. We show that selectively targeting the CoREST co-repressor complex with the representative compound Rodin-A results in increased spine density and synaptic proteins, and improved long-term potentiation in a mouse model at doses that provide a substantial safety margin that would enable chronic treatment. The CoREST-selective HDAC inhibitor Rodin-A thus represents a promising therapeutic strategy in targeting synaptic pathology involved in neurologic disorders.

KEYWORDS: HDAC, CoREST, synaptopathy, prosynaptic, synaptic resilience, neurodegenerative

\section{INTRODUCTION}

Synaptic dysfunction, or synaptopathy, is a pathological feature in many neurodegenerative disorders, including Alzheimer's disease, and synaptic loss correlates closely with cognitive decline in both humans and animals. ${ }^{1-7}$ Emerging evidence implicates epigenetic dysregulation in cognitive and neurodegenerative disorders. ${ }^{8-12}$ Post-translational epigenetic modifications of histone proteins, such as acetylation, play a central role in regulating neuronal gene expression and brain function. Many studies with HDAC inhibitors (HDACi) have shown increases in histone acetylation and enhanced synaptic plasticity, learning, and memory, providing promise for the use of HDACi in treating synaptopathies. ${ }^{13-15}$ However, the HDACi tested in these studies target multiple HDAC isoforms and have displayed dose-limiting hematological toxicities typically associated with HDACi. ${ }^{16,17}$ For conditions that are likely to require chronic dosing, such as neurologic disorders, these hematological toxicities are a significant safety concern and have relegated the use of HDACi only to in vitro and animal model studies rather than clinical treatment of patients afflicted with these debilitating conditions. To harness the potential of HDACi to treat neurologic disorders, much safer compounds are required to enable long-term treatment of patients. More selective inhibitors of HDACs have been explored to test whether improved selectivity could maintain efficacy and minimize the dose-limiting toxicities, but with limited success. Strategies pursued toward this goal have included isoform and kinetic selectivity. ${ }^{18,19}$

Received: November 8, 2018

Accepted: November 29, 2018

Published: November 29, 2018 
A

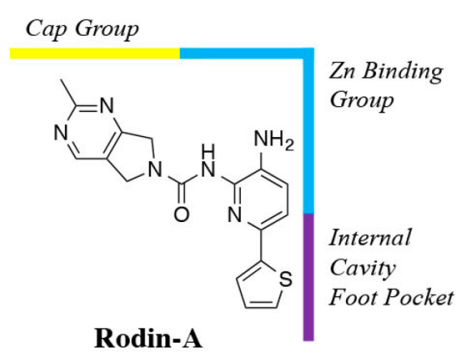<smiles>COCCn1cc2c(c1)CN(C(=O)Nc1nc(-c3ccc(F)cc3F)ccc1N)C2</smiles>

Rodin-B

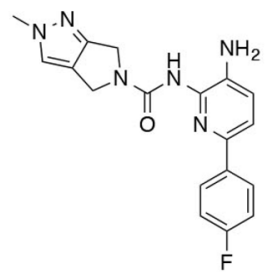

Rodin-C<smiles>COCc1cc2c(cn1)CN(C(=O)Nc1nc(-c3ccc(F)cc3)ccc1N)C2</smiles>

Rodin-D<smiles>CC(=O)Nc1ccc(C(=O)Nc2ccccc2N)cc1</smiles>

CI-994<smiles>CC(=O)Nc1ccc(C(=O)Nc2cc(-c3cccs3)ccc2N)cc1</smiles>

Cpd-60<smiles>O=C(CCCCCCC(=O)Nc1ccccc1)NO</smiles>

SAHA
B

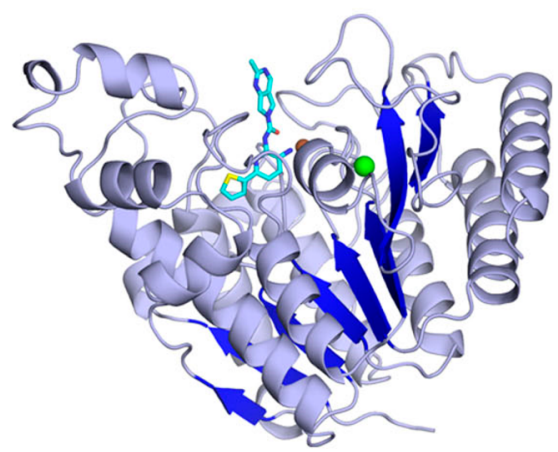

C

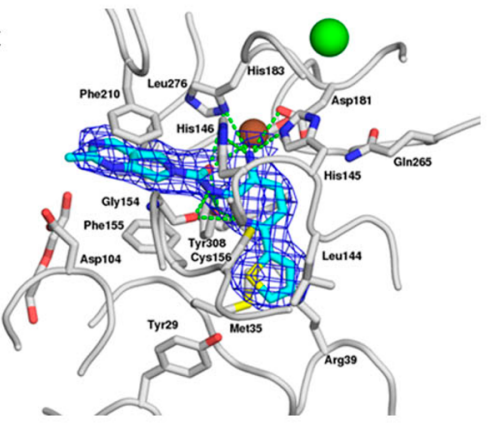

Figure 1. Structures of HDACi and crystal structure of Rodin-A with HDAC2. (A) Structures of four Rodin 3-amino-pyridine-2-urea HDACi and three published HDACi. (B) X-ray crystal structure of HDAC2 in complex with Rodin-A. Overall structure of HDAC2 containing the ligand Rodin-A shown as a ribbon diagram. One monomer of HDAC2 is shown as a ribbon representation. The ligand Rodin-A is shown as a stick model, colored according to the chemical atom type ( $\mathrm{C}_{\text {Rodin-A }}$ in cyan, $\mathrm{N}$ in blue, $\mathrm{O}$ in red, and $\mathrm{S}$ in yellow). (C) Binding pocket of HDAC2 containing the ligand Rodin-A. The ligand and neighboring protein side chains are shown as a stick model, colored according to the chemical atom type $\left(\mathrm{C}_{\mathrm{Rodin}-\mathrm{A}}\right.$ in cyan, $\mathrm{C}_{\mathrm{HDAC} 2}$ in gray, $\mathrm{N}$ in blue, $\mathrm{O}$ in red, and $\mathrm{S}$ in yellow). The ligand molecule is superimposed with the refined $2 F_{\mathrm{o}}-F_{\mathrm{c}}$ electron density map contoured at 1.0 $\sigma$. Hydrogen bonds are indicated as green dotted lines. For details of data collection, see SI (Tables S2 and S3).

The 18 human HDAC enzymes are divided into four classes based on sequence homology and function. The class I (HDAC1, HDAC2, HDAC3, and HDAC8), class II (HDAC4, HDAC5, HDAC6, HDAC7, HDAC9, and HDAC10), and class IV (HDAC11) members are $\mathrm{Zn}^{+2}$ dependent, while the class III sirtuins (SIRT1-7) are $\mathrm{NAD}^{+}$dependent. ${ }^{8}$ Selective targeting of the class I HDAC isoforms HDAC1, HDAC2, and HDAC3 has been achieved using benzamide and other orthoaminoanilide inhibitors. ${ }^{15,18-20}$ These class I HDACs exist in multiprotein co-repressor complexes, including the CoREST, NuRD, Sin3, and SMRT/NCoR complexes, through which they differentially engage chromatin and deacetylate specific histone and non-histone sites. ${ }^{8}$ The pioneering work by Bantscheff et al. demonstrated via chemoproteomics that the benzamides CI-994 and BML-210 were selective for a subset of HDAC co-repressor complexes, binding the CoREST, NuRD, and NCoR complexes, but not the Sin 3 complex. ${ }^{21}$ This was the first demonstration that some measure of HDACi selectivity beyond the isoform level was possible, achieving limited selectivity between the HDAC-co-repressor complexes. Despite this additional level of co-repressor complex selectivity, CI-994 still displayed significant hematological toxicity ${ }^{17}$ and maintained the prosynaptic effects at both the structural and functional levels. ${ }^{22}$ Of the different co-repressor complexes, the CoREST complex preferentially associates with HDAC2 in the brain and has been shown to have a key function in repressing neuronal gene expression., ${ }^{8,9,23,24}$ We hypothesized that selectively targeting HDACs associated with the CoREST complex could limit peripheral toxicity while maintaining beneficial neuronal effects.

Here we describe our design of a series of molecules that specifically targets the HDACs in the CoREST co-repressor complex and maintains prosynaptic effects while minimizing deleterious hematopoietic toxicity.

\section{RESULTS}

Rodin Compounds Selectively Inhibit HDAC1 and HDAC2. To test the hypothesis that a selective HDACCoREST co-repressor complex inhibitor would maintain prosynaptic effects and improve the safety profile, we embarked on a medicinal chemistry campaign to identify molecules with these properties. We separated our chemistry efforts into two design stages. In the first stage, we designed new HDACi core scaffolds that maintained the inhibitory activity toward HDAC1 and HDAC2, similar to the classic benzamide scaffolds. In the second design stage, we 
Table 1. In Vitro Inhibitory Profile of Rodin Compounds, CI-994, and Cpd-60 ${ }^{a}$

\begin{tabular}{|c|c|c|c|c|c|c|}
\hline \multirow[b]{2}{*}{ target } & \multicolumn{6}{|c|}{$\mathrm{IC}_{50}(\mu \mathrm{M})$} \\
\hline & Rodin-A & Rodin-B & Rodin-C & Rodin-D & CI-994 & Cpd-60 \\
\hline HDAC1 & 0.15 & 0.27 & 0.059 & 0.12 & 0.62 & 0.008 \\
\hline HDAC2 & 0.43 & 0.28 & 0.18 & 0.28 & 0.54 & 0.031 \\
\hline HDAC3 & $>30$ & 27.6 & 20.2 & $>30$ & 0.28 & 2.59 \\
\hline HDAC4 & $>30$ & $>30$ & $>30$ & $>30$ & $>30$ & $>30$ \\
\hline HDAC5 & $>30$ & $>30$ & $>30$ & $>30$ & $>30$ & $>30$ \\
\hline HDAC6 & $>30$ & $>30$ & $>30$ & $>30$ & $>30$ & $>30$ \\
\hline HDAC7 & $>30$ & $>30$ & $>30$ & $>30$ & $>30$ & $>30$ \\
\hline HDAC8 & $>30$ & $>30$ & $>30$ & $>30$ & $>30$ & $>30$ \\
\hline HDAC9 & $>30$ & $>30$ & $>30$ & $>30$ & $>30$ & $>30$ \\
\hline HDAC 10 & $>30$ & $>30$ & $>30$ & $>30$ & 8.95 & $>30$ \\
\hline HDAC 11 & $>30$ & $>30$ & 5.39 & 11.8 & $>30$ & 5.79 \\
\hline
\end{tabular}

${ }^{a}$ Inhibitory activity of Rodin-A, Rodin-B, Rodin-C, Rodin-D, CI-994, and Cpd-60 toward deacetylase activity of HDAC isoforms $1-11$ ( $N \geq 3$ ).

Table 2. HDAC Co-repressor Complex Deacetylase Activity Inhibition Profile of Rodin Compounds and of CI-994, Cpd-60, and SAHA ${ }^{a}$

\begin{tabular}{lccccccc} 
& \multicolumn{5}{c}{} & $\mathrm{IC}_{50}(\mu \mathrm{M})$ & \\
\cline { 2 - 8 } target & Rodin-A & Rodin-B & Rodin-C & Rodin-D & CI-994 & Cpd-60 & SAHA \\
CoREST & 1.80 & 0.50 & 0.38 & 0.49 & 1.82 & 0.16 & 0.10 \\
Sin3 & $>250$ & $>250$ & $>250$ & $>250$ & $>250$ & 191 & 0.11 \\
NuRD & 222 & $>250$ & 202 & $>250$ & 8.43 & 107 & 0.076 \\
NCoR & 160 & 88 & 52 & 209 & 0.86 & 4.03 & 0.14 \\
Fold CoREST selectivity & $>138$ & $>499$ & $>649$ & $>510$ & $>137$ & 1224 & 1.1 \\
vs Sin3 & 123 & $>499$ & 524 & $>510$ & 4.6 & 686 & 0.8 \\
vs NuRD & 88 & 175 & 135 & 426 & 0.5 & 26
\end{tabular}

${ }^{a}$ Inhibitory activity of Rodin-A, Rodin-B, Rodin-C, Rodin-D, CI-994, Cpd-60, and SAHA toward deacetylase activity of co-immunoprecipitated corepressor complexes CoREST, Sin3A, NuRD, and NCoR. IC I0 $_{50}$ values for co-repressor complex co-immunoprecipitation activity assays are reported as the average of two experimental replicates. Each experiment includes technical replicates. See Methods for details.

implemented an in vitro predictive safety assay in human bone marrow cells to optimize the structure-activity relationship (SAR) for human hematological safety in this series of compounds while maintaining selective HDAC inhibitory activity.

Encouraged by multiple reports of isoform selectivity toward HDAC1 and HDAC2 achieved with benzamides and other ortho-aminoanilide containing appendages, which occupy the hydrophobic internal cavity "foot pocket" in the HDAC active site, ${ }^{18-20,25-28}$ we devised a strategy to modify the aniline core and $\mathrm{Zn}^{+2}$-chelating pharmacophore of class I selective compounds such as CI-994 and Cpd-60 (Figure 1A) as a means of honing the selectivity profile. By replacing the core diamino-aniline with other diamino-heterocycles, we tuned down the $\mathrm{Zn}^{+2}$ chelating ability while simultaneously occupying the "foot pocket", with the aim of achieving the right balance of electrostatic properties. To test this hypothesis, a range of different heterocyclic replacements for the diaminoaniline core were explored, and most modifications resulted in a decrease in HDAC inhibitory activity (data not shown), but the 3-amino-pyridine-2-urea chemotype emerged with the best balance of HDAC potency and drug-like properties. Iterative design, synthesis, and compound optimization efforts resulted in a series of compounds represented by Rodin-A, Rodin-B, Rodin-C, and Rodin-D, which are all novel class I HDACi featuring the 3-amino-pyridine-2-urea core structure (Figure 1A). Key structural features include the central diaminopyridine ring, fused bicyclic pyrrolidine ureas, and the lipophilic "foot pocket" appendage. The four compounds feature four different cap groups (highlighted as the yellow region of Rodin-A in Figure 1A) and three different foot pockets (purple region), while all utilize the same $\mathrm{Zn}^{+2}$ chelating group (blue region).

In profiling against isolated recombinant HDAC isoforms for inhibition of enzymatic activity, these compounds selectively inhibited the HDAC1 and HDAC2 isoforms (Table 1). Modest inhibitory activity toward HDAC11 was exhibited by Rodin-C and Rodin-D. The well-studied HDACi CI-994 ${ }^{22,29}$ and $\mathrm{Cpd}-60^{20,25}$ were also profiled as key comparators. The benzamide CI-994 inhibited HDAC1, HDAC2, and HDAC3, with modest inhibition of HDAC10. The more elaborated Cpd-60, containing the 2-thiophenyl substituent on the CI-994 benzamide core, potently inhibited HDAC1 and HDAC2 and showed modest inhibition of HDAC3 and HDAC11.

Binding Pose of Rodin-A Confirmed by X-ray Cocrystal Structure with HDAC2. An X-ray cocrystal structure of Rodin-A with HDAC2 at a resolution of $2.25 \AA$ confirmed the predicted binding pose in the active site, with the 3-amino-pyridine-2-urea pharmacophore chelating the $\mathrm{Zn}^{+2}$ and the 2-thiophenyl group occupying the $14 \AA$ hydrophobic "foot pocket", a feature that has previously been described to result in selective inhibition of HDAC1/2 over HDAC3 $^{19,20,25-28}$ (Figure 1B,C). The bicyclic urea cap group of Rodin-A participates in $\pi$-stacking interactions with Phe210 and Phe155 of HDAC2. The urea $\mathrm{NH}$ participates in a backbone interaction with Gly154, and the $\mathrm{NH}_{2}$ participates in a hydrogen bond network with His145 and His146, in addition 
to binding the $\mathrm{Zn}^{+2}$. This binding mode is consistent with the observed binding mode of Cpd-60 with HDAC2. ${ }^{27}$

Rodin Compounds Selectively Inhibit the Deacetylase Activity of the HDAC-CoREST Complex. Since HDAC1, HDAC2, and HDAC3 are components of multiprotein co-repressor complexes, inhibition of the deacetylase activity of the enzymes as members of complexes would be a more physiologically relevant measure of the HDAC activity of the compounds. $^{21,30,31}$ To explore the ability of the 3-aminopyridine-2-urea compound series to inhibit specific HDAC corepressor complexes, we implemented co-immunoprecipitation (co-IP) activity assays to measure the ability of the Rodin compounds, CI-994, Cpd-60, and SAHA to inhibit the HDAC activity within CoREST, Sin3, NuRD, and NCoR co-repressor complexes when purified and isolated from a cell lysate. Of the complexes investigated, Rodin-A, Rodin-B, Rodin- $\mathrm{C}$, and Rodin-D primarily inhibit only the HDAC-CoREST complex activity (Table 2, Figure 2). The co-IP assay confirmed the
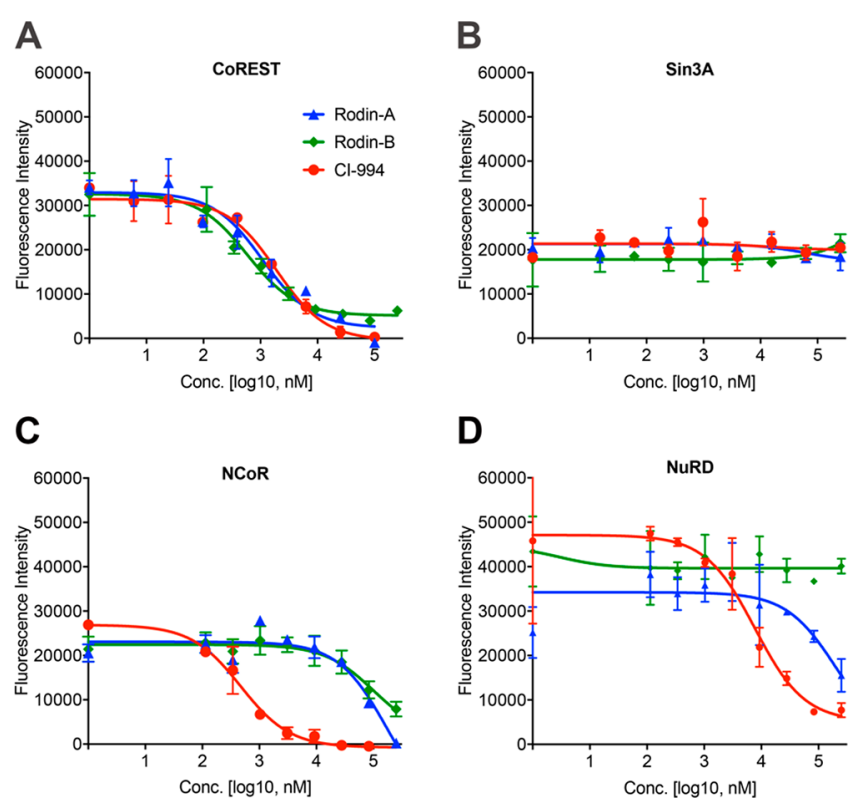

Figure 2. Rodin-A and Rodin-B selectively inhibit activity of the HDAC-CoREST complex. Overlaid inhibition curves of Rodin-A, Rodin-B, and CI-994 for the HDAC-containing isolated CoREST (A), Sin3A (B), NCoR (C), and NuRD (D) complexes in the coimmunoprecipitation complex deacetylase activity assays (technical duplicates; error bars are SD).

earlier published findings that CI-994 inhibits the HDAC activity of CoREST, NuRD, and NCoR but not Sin3, while SAHA inhibits all the isolated HDAC complexes. ${ }^{21,30}$ Our studies also demonstrate that Cpd-60, which adds the 2thiophenyl group to the CI-994 scaffold to extend into the "foot pocket" cavity, inhibits the CoREST and NCoR complexes.

The HDAC-CoREST co-repressor complex also contains the lysine-specific histone demethylase 1 (LSD1). While strategies for targeting the LSD1-CoREST complex ${ }^{32}$ or the LSD1-HDAC-CoREST complex have been reported via dual LSD1/HDACi, ${ }^{33,34}$ these make no mention of selectivity over other HDAC complexes. Rodin compounds were screened against LSD1 and LSD1-CoREST and showed no inhibition of the LSD1 activity, confirming that they target the HDACs in the CoREST complex and do not have an effect on LSD1 (SI; Table S4).

Rodin Compounds Show Less Hematological Toxicity in Vitro than Cl-994 and Cpd-60. To explore the impact of complex selectivity on hematological toxicity, in vitro assays were run in human bone marrow cells to predict hematological effects in humans. The potential effects on human erythroid and myeloid progenitors of the CoREST selective inhibitors (Rodin-A, Rodin-B, Rodin-C, and Rodin-D), CI-994, and Cpd60 were assessed in a colony forming unit (CFU) cell assay system, which has been shown to be predictive for clinical neutropenia and anemia. ${ }^{35}$ Compound treated cells were cultured for 14 days, whereupon the relative safety of compounds was assessed by counting cell colonies and comparing between control and compound treated plates. After 14 days at $10 \mu \mathrm{M}$ compound treatment, the in vitro hematological effects of the CoREST selective inhibitors Rodin-A, Rodin-B, and Rodin-D were mild, with all having greater than $59 \%$ of control remaining in the myeloid progenitors (Table 3 ). Rodin-C showed more toxicity, with

Table 3. In Vitro Hematological Safety Profiling of Rodin Compounds and of CI-994 and Cpd-60 ${ }^{a}$

\begin{tabular}{lcccccc}
\hline target & Rodin-A & Rodin-B & Rodin-C & Rodin-D & $\begin{array}{c}\text { CI- } \\
994\end{array}$ & $\begin{array}{c}\text { Cpd- } \\
60\end{array}$ \\
$\begin{array}{l}\text { myeloid } \\
\text { progenitors: } \%\end{array}$ & 59 & 63 & 30 & 59 & 0 & 0 \\
$\begin{array}{c}\text { control at } 10 \mu \mathrm{M} \\
\text { erythroid }\end{array}$ & & & & & & \\
$\begin{array}{l}\text { progenitors: } \% \\
\text { control at } 10 \mu \mathrm{M}\end{array}$ & & 40 & 16 & 23 & 0 & 0 \\
\end{tabular}

${ }^{a}$ In vitro hematological safety assays: effects on human myeloid and erythroid progenitors using colony forming cell (CFU) assays, assessed in a semi-solid, methylcellulose-based culture system. The mean and SEM of three replicate cultures were calculated for progenitors of each category (myeloid and erythroid). Compounds were dosed at $0.4,2$, and $10 \mu \mathrm{M}$. See Methods for details.

$30 \%$ of control remaining in the myeloid progenitors. The erythroid progenitors were more sensitive to compound treatment in all cases. The class I selective HDACi CI-994 (HDAC1, 2, 3) and Cpd-60 (HDAC1, 2) had severe toxic effects on both the myeloid and erythroid progenitor cells, with $0 \%$ control remaining after $10 \mu \mathrm{M}$ compound treatment.

Because Rodin-A demonstrated a similar CoREST complex $\mathrm{IC}_{50}$ to CI-994 and a clean isoform inhibition profile (HDAC1 and HDAC2 at similar IC $_{50}$ to CI-994), it represented the best comparator compound to CI-994 to explore the effects of selective CoREST inhibition on synapses. Based on this similarity, in vitro ADME and safety profiles, and pharmacokinetic profile, a thorough in vitro and in vivo characterization was conducted on this novel and representative HDACCoREST co-repressor selective compound.

Rodin-A Increases H3K9 Acetylation. The most proximal effect of HDACi is an increase in histone acetylation at multiple sites in the genome (typically tracked as global changes in the acetylation status of specific histone lysine side chains). Traditionally, several key histone lysines linked to gene regulation are monitored during HDACi treatment; ${ }^{36}$ $\mathrm{H} 3 \mathrm{~K} 9$ is a commonly analyzed position, and we report effects of Rodin-A on this position in K562 cells. Rodin-A treatment of $\mathrm{K} 562$ cells stimulated histone acetylation with a similar potency as the less selective CI-994 (Figure 3A,B; Figure S1). Both CI-994 and Rodin-A increase the levels of acetylation at 


\section{A}

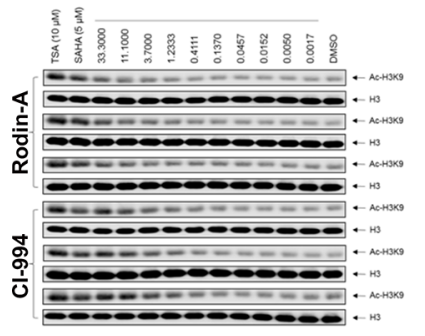

B

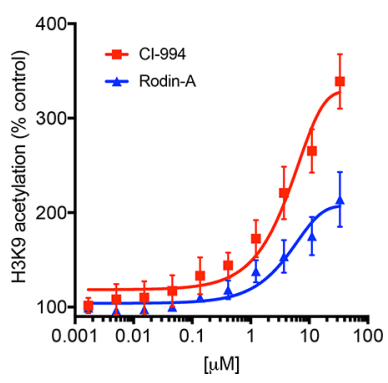

Figure 3. Inhibition of histone deacetylation at site $\mathrm{H} 3 \mathrm{~K} 9$ in vitro in a dose-dependent manner by Rodin-A and CI-994. CI-994 and RodinA treatment of $\mathrm{K} 562$ cells results in increased levels of acetylation at position lysine 9 on histone $\mathrm{H} 3$ (Ac-H3K9), relative to treatment with DMSO after $24 \mathrm{~h}$. (Western blot image in left panel, dose-response effect in right panel, $n=3$ independent treatments; for all figures, error bars are SEM).

position lysine 9 on histone $\mathrm{H} 3$ (Ac-H3K9), relative to treatment with DMSO, in K562 cells treated in vitro for $24 \mathrm{~h}$. The more complex-selective Rodin- $\mathrm{A}$ has a lower magnitude of effect on global Ac-H3K9 acetylation than the less selective CI994 when each are dosed over the same dose range up to 100 $\mu \mathrm{M}$ in a dose-response treatment.

Rodin-A Increases Density of Total and Thin Spines. HDAC inhibition has been shown to enhance synaptic structure and function. ${ }^{22}$ To investigate whether chronic treatment with Rodin-A and CI-994, with different corepressor complex selectivity profiles, affects structural plasticity to a similar degree, we measured dendritic spines in the hippocampus following 14 days of daily administration. Rodin-A (0.1, 0.3, 1, 3, and 6 mg/kg/day), CI-994 (1 and 3 $\mathrm{mg} / \mathrm{kg} /$ day), or vehicle ( $20 \% \mathrm{HP} \beta \mathrm{CD}$ ) was dosed orally to wild-type (WT) mice for 14 days, and the mice were sacrificed $24 \mathrm{~h}$ after the final dose. Dendritic spine density and morphology were evaluated in the CA1 region of the dorsal hippocampus, using ballistic dye labeling. The $6 \mathrm{mg} / \mathrm{kg}$ dose of Rodin-A was chosen to match the predicted free brain exposures of CI-994 at the efficacious dose of $1 \mathrm{mg} / \mathrm{kg}$ based on PK experiments and in vitro protein binding data (SI; Table S5). Rodin-A treatment resulted in a significant increase in dendritic spine density when compared to vehicle-treated controls (Figure 4A,B). No significant changes were observed at the lower doses of 0.1 or $0.3 \mathrm{mg} / \mathrm{kg}$ (data not shown). The strong prosynaptic effects at the 1 and $3 \mathrm{mg} / \mathrm{kg}$ doses can be explained by high concentration of free drug in brain as demonstrated in a separate microdialysis experiment (Figure 4C; SI, Table S6). Mice treated with CI-994 at 1 and $3 \mathrm{mg} / \mathrm{kg}$ displayed significant increases in spine density compared to vehicle-treated animals, which were similar to Rodin-A (Figure 4B).

When spine morphology is analyzed, chronic treatment with Rodin-A produced a dose-dependent increase in thin spines, with significant effects measured at all tested doses (SI; Figure S2A). In contrast, there were no significant changes in mushroom and stubby spine density (SI; Figure S2B,C). To further characterize the Rodin- $\mathrm{A}$ mediated effects on spine density, we also investigated both the duration of dosing required to mediate the increase in spine density and the duration of increase following 14 days of dosing. Chronic treatment with Rodin-A ( $3 \mathrm{mg} / \mathrm{kg} /$ day) produced a time-

\section{A}

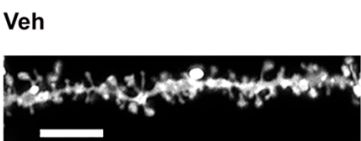

Rodin-A

B

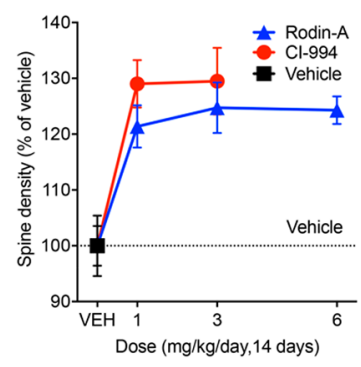

C
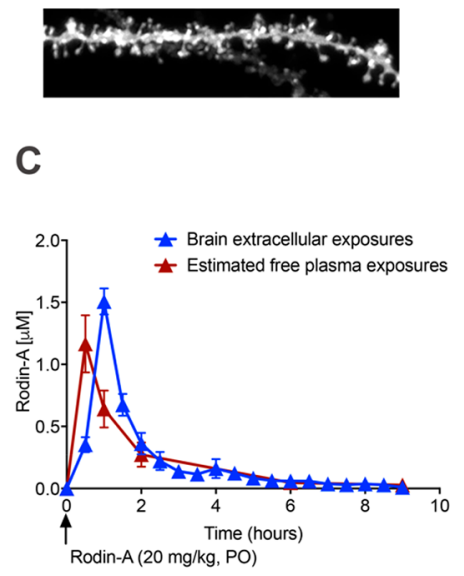

E
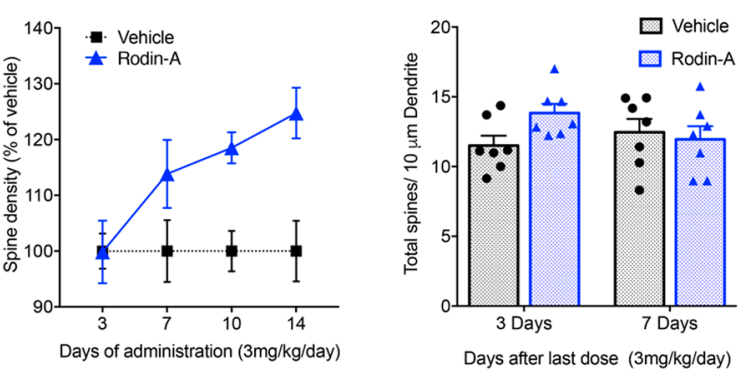

Figure 4. Rodin-A increases synaptic density in mice. (A) Representative three-dimensional images of dendritic spines after ballistic dye labeling (scale bar, $5 \mu \mathrm{m}$ ). (B) Quantification of total dendritic spine density in hippocampal pyramidal neurons in WT mice after 14 days of treatment with Rodin-A $(n=7)$ or CI-994 ( $n=$ 5). Significant increases occur in spine density following treatment of mice with different doses of Rodin-A (mean \pm SEM, one-way ANOVA and Dunnett's post hoc analysis; $1 \mathrm{mg} / \mathrm{kg}, p=0.004 ; 3 \mathrm{mg} /$ $\mathrm{kg} p=0.001 ;$ and $6 \mathrm{mg} / \mathrm{kg}, p=0.0012)$ and CI-994 $(1 \mathrm{mg} / \mathrm{kg}, p=$ $0.02 ; 3 \mathrm{mg} / \mathrm{kg}, p=0.018$ ). (C) PK curves from mouse microdialysis experiment with Rodin-A dosed at $20 \mathrm{mg} / \mathrm{kg}$. Exposure curves for brain dialysate showing free exposure in brain at different time points overlaid with estimated free plasma exposures calculated using in vitro plasma protein binding data $\left(f_{\mathrm{u}}=25.1 \%\right.$ in mouse plasma in vitro). Free brain-to-plasma ratio $\left(K_{\text {puu }}\right)$ at brain $C_{\max }=2.4$. (D) Total spine density quantification after different duration of daily treatment with Rodin-A ( $n=7$ animals each). Spine density does not significantly change after 3 or 7 days of treatment but significantly increased after 10 days of dosing (mean \pm SEM, unpaired $t$ test, $p=0.0016$ ). (E) Quantification of spine density at different days after last dose $(n=7$ animals each) indicates a reversible effect of the drug after 7 days from the last dose. Error bars are SEM.

dependent increase in spines, with no changes in spine density after 3 or 7 days of treatment but a statistically significant increase in total spine density after 10 days of dosing (Figure 4D). Following termination of dosing ( 14 days, $3 \mathrm{mg} / \mathrm{kg} /$ day), the spine density gradually decreased over a 7 day period and returned to vehicle-treated levels at day 7 post-treatment (Figure 4E). Taken together, our findings demonstrate that chronic treatment with Rodin-A resulted in increased synaptic density that gradually developed over a 10 day period and has returned to baseline 7 days following termination of dosing. This confirms our hypothesis that chronic treatment is likely required for a selective HDACi to achieve desired 

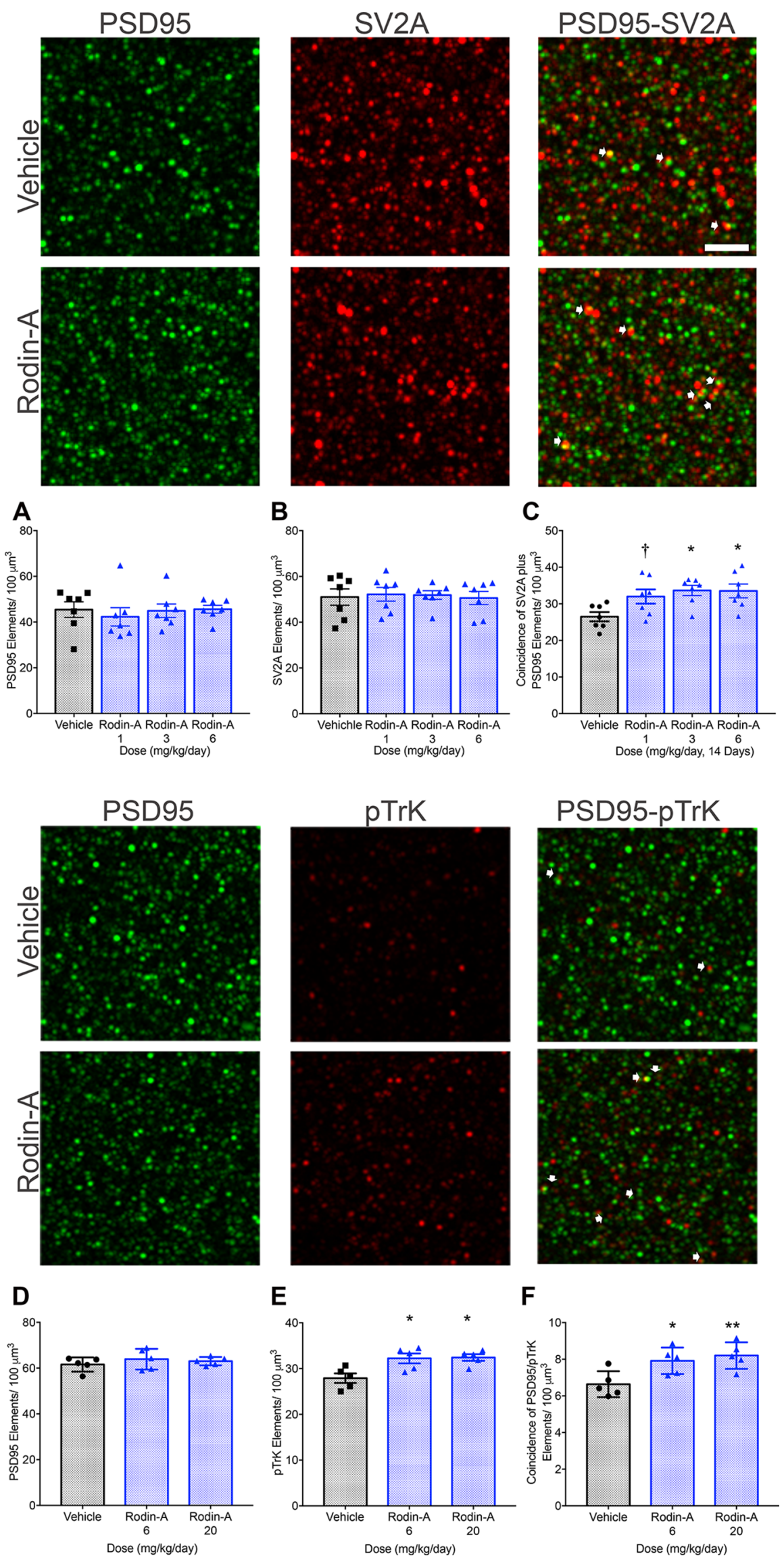

Figure 5. Immunohistochemical analysis of pre- and postsynaptic elements. Multiple doses of Rodin-A in WT mice do not change the total number of synaptic PSD95 (A) and SV2A (B) proteins but significantly increase coincidence of synaptic proteins SV2A and PSD95 (C, $n=7$ ), in the CA1 
Figure 5. continued

dorsal hippocampus (scale bar, $2 \mu \mathrm{m}$ ). Similarly, treatment with Rodin-A significantly increases pTrk elements and coincidence of $\mathrm{pTrK}(\mathrm{D}, n=5)$ and PSD95 (E, F, $n=5$ ) in the CA1 dorsal hippocampus (mean \pm SEM, one-way ANOVA and Dunnett's post hoc analysis. ${ }^{*} p \leq 0.05$; ** $p \leq 0.01$; $* * * p \leq 0.001 ; * * * * p \leq 0.0001)$.
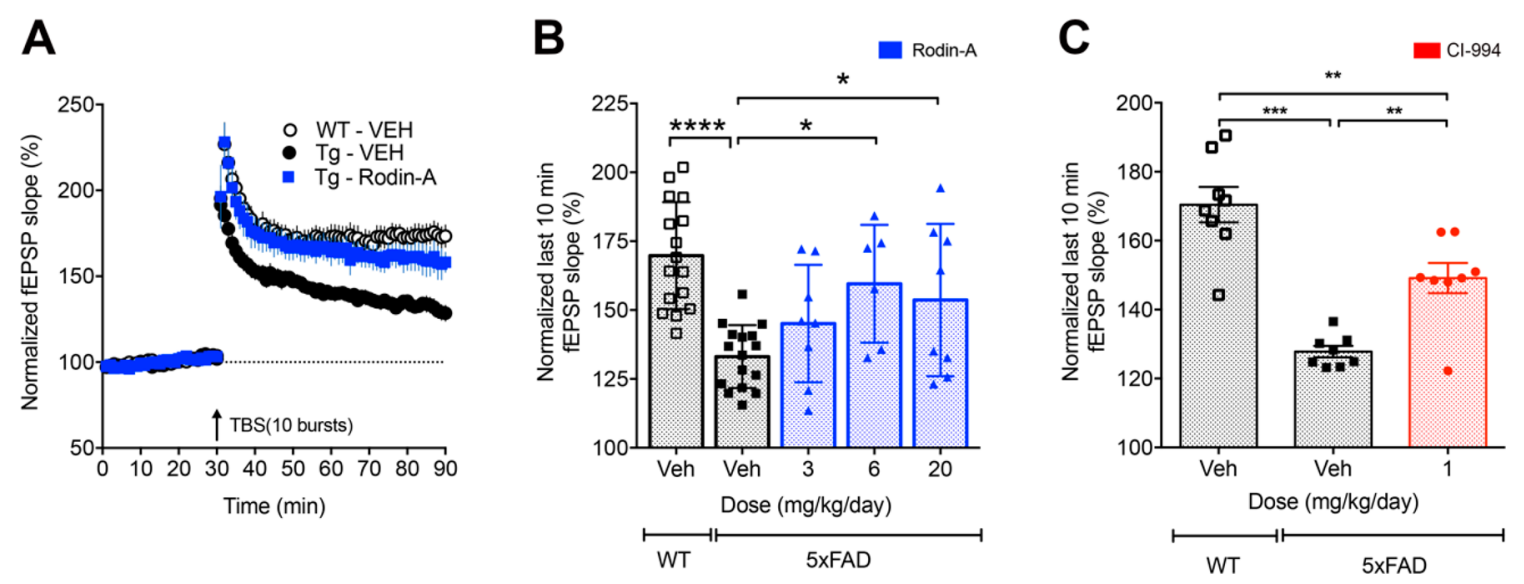

Figure 6. Compound effects of Rodin-A and CI-994 on impaired hippocampal LTP. (A) Effects of Rodin-A treatment on normalized last 10 min fEPSP slope $\%$ in hippocampus of transgenic 5xFAD mice. Average fEPSP change for aged, $10-12$ months old, 5xFAD vehicle treated mice $(n=$ 8), matched WT vehicle treated mice $(n=9)$, and aged, $10-12$ months old, 5xFAD mice treated with $6 \mathrm{mg} / \mathrm{kg}$ Rodin-A, po, for 14 days $(n=6)$. (B) Treatment with $3 \mathrm{mg} / \mathrm{kg}, 6 \mathrm{mg} / \mathrm{kg}$, and $20 \mathrm{mg} / \mathrm{kg}$ doses of Rodin-A improves impaired LTP in aged 5xFAD mice relative to vehicle treated animals (combination of two experiments; $n=16,16,6$, and 8 for WT Veh, 5xFAD Veh, $6 \mathrm{mg} / \mathrm{kg}$, and $20 \mathrm{mg} / \mathrm{kg}$ treated animals, respectively). (C) Dosing aged, 10-12 months old, 5xFAD mice with $1 \mathrm{mg} / \mathrm{kg}$ of CI-994, po (all groups $n=8$ ), for 14 days improves impaired LTP in treated mice relative to vehicle. For all figures, error bars are SEM. For panels B and C, statistical analysis was by one-way ANOVA followed by a HolmSidak post hoc test $(* p<0.05, * * p<0.01, * * * p<0.005)$.

prosynaptic effects, thus increasing the safety requirements for a neurotherapeutic HDACi. The findings also suggest that after chronic treatment, those structural changes are sustained for a period of time postdosing.

Rodin-A Increases Coincidence of Synaptic Proteins. To further characterize the effects of chronic administration of Rodin-A on the structure of excitatory synapses, presynaptic vesicle protein 2A (SV2A) and postsynaptic density protein 95 (PSD95) proteins were quantified by immunofluorescence in the dorsal hippocampus of WT mice that had been treated with Rodin-A daily for 14 days. ${ }^{37,38}$ Structurally mature synapses were identified by colocalization of pre- and postsynaptic SV2A and PSD95 puncta. Treatment with Rodin-A led to a dose-dependent increase in the coincidence of SV2A and PSD95 (Figure 5C). The low dose produced a $20 \%$ increase that did not reach significance, while the 3 and 6 $\mathrm{mg} / \mathrm{kg}$ doses led to a significant increase in SV2A-PSD95 coincidence $(\sim 27 \%)$ that matches the increase in spine density (Figure 4B). There was, however, no effect on total PSD95 and SV2A elements, separately (Figure 5A,B).

A key mediator of structural and functional synaptic changes is the brain-derived neurotrophic factor (BDNF), which acts predominantly via $\mathrm{TrkB}$ receptors in hippocampal neurons. ${ }^{39,40}$ Increases in BDNF binding to and signaling through TrkB should be accompanied by increases in phosphorylated TrkB ( $\mathrm{pTrkB}$ ) at postsynaptic dendrites of excitatory synapses in hippocampus. ${ }^{40}$ We therefore investigated whether chronic treatment with Rodin-A affected $\mathrm{pTrkB}$ protein in the CA1 region of the dorsal hippocampus in WT mice. Excitatory synapses were identified by PSD95, which is highly enriched at glutamatergic synapses. ${ }^{41}$ Rodin-A treatment produced a significant increase in both total pTrk levels (Figure 5D) and in the coincidence of pTrk and PSD95 (Figure 5F). There was no effect of treatment with Rodin-A on total PSD95 levels (Figure 5E).

Rodin-A Improves Impaired LTP in a 5xFAD Mouse Model. Synaptic plasticity encompasses structural changes, dendritic spine plasticity, and the resulting physiological plasticity, including long-term potentiation (LTP), which together are considered the foundation of learning and memory. LTP is a persistent strengthening of synapses, with a long-lasting increase in synaptic efficacy and in signal transmission between neurons, which has been shown to be related to dendritic spine size and numbers. ${ }^{42,43}$

To evaluate the effect of Rodin-A on LTP, we employed the $5 x F A D$ transgenic mouse model of amyloid pathology, in which mice begin to display deficits in LTP by the age of 4-7 months. ${ }^{44}$ Aged 5xFAD mice were treated with vehicle or three doses of Rodin-A and compared to an age-matched cohort of $\mathrm{WT}$ animals treated with vehicle (Figure $6 \mathrm{~A}, \mathrm{~B}$ ). The $5 \mathrm{xFAD}$ animals display an impaired LTP relative to WT animals, and in this model, treatment with Rodin-A (3, 6, and $20 \mathrm{mg} / \mathrm{kg}$; Figure 6B) for 14 days stimulated a dose-related improvement of the impaired LTP similar to the results seen with CI-994 at $1 \mathrm{mg} / \mathrm{kg}$ (Figure 6C).

In Vivo Safety Profile of Rodin-A in Rats and Dogs. In order to confirm the in vitro findings that suggest this series of CoREST-selective HDACi possess an improved hematological safety profile compared to less selective compounds with respect to co-repressor complexes in vivo, we profiled Rodin-A in toxicology studies in male Sprague-Dawley rats $(n=20)$ and male beagle dogs $(n=15)$, with daily oral dosing for 14 days. There were no Rodin-A related observations in male Sprague-Dawley rats after 14 days daily oral dosing at $30 \mathrm{mg}$ / $\mathrm{kg}$ or $45 \mathrm{mg} / \mathrm{kg}$. The no-observed-adverse-effect level (NOAEL) was considered to be $45 \mathrm{mg} / \mathrm{kg}$ (day 14, AUC 
Table 4. Rodin-A Toxicokinetic Parameters in Rats and Dogs Following Repeated Daily Oral Administration for 14 Days

\begin{tabular}{|c|c|c|c|c|c|c|}
\hline & \multicolumn{3}{|c|}{$\mathrm{SD}$ rat $^{a}$} & \multicolumn{3}{|c|}{ beagle $\operatorname{dog}^{b}$} \\
\hline & $30 \mathrm{mg} / \mathrm{kg}$ & $45 \mathrm{mg} / \mathrm{kg}$ & $60 \mathrm{mg} / \mathrm{kg}$ & $45 \mathrm{mg} / \mathrm{kg}$ & $60 \mathrm{mg} / \mathrm{kg}$ & $120 \mathrm{mg} / \mathrm{kg}$ \\
\hline \multicolumn{7}{|c|}{$C_{\max }(\mathrm{ng} / \mathrm{mL})$} \\
\hline \multicolumn{6}{|c|}{$\operatorname{AUC}(\mathrm{ng} \cdot \mathrm{h} / \mathrm{mL})$} & $18600 \pm 7410$ \\
\hline day 14 & $8240 \pm 1940$ & $13200 \pm 4760$ & $28700 \pm 7570$ & $11487 \pm 1918$ & $13000 \pm 5790$ & $25000 \pm 14300$ \\
\hline
\end{tabular}

$13200 \mathrm{ng} \cdot \mathrm{h} / \mathrm{mL}, C_{\max } 3780 \mathrm{ng} / \mathrm{mL}$; Table 4). The $60 \mathrm{mg} / \mathrm{kg}$ dose group of Rodin-A in rats showed hematological and bone marrow effects and microscopic findings in the testes. In male beagle dogs, after daily oral dosing for 14 days at $45 \mathrm{mg} / \mathrm{kg}, 60$ $\mathrm{mg} / \mathrm{kg}$, and $120 \mathrm{mg} / \mathrm{kg}$, there were no target organ effects observed at any dose levels, and the NOAEL was considered to be $120 \mathrm{mg} / \mathrm{kg}$ (day 14, AUC of $25000 \mathrm{ng} \cdot \mathrm{h} / \mathrm{mL}, C_{\max }$ of $18600 \mathrm{ng} \cdot \mathrm{h} / \mathrm{mL}$; Table 4).

\section{DISCUSSION}

As a result of our drug discovery program focused on identifying safer HDACi to treat neurologic disorders, we have identified a series of 3-amino-pyridine-2-urea compounds that selectively inhibit the activity of the HDAC-CoREST corepressor complex. In comparing inhibition of individual HDAC isoforms, the Rodin compounds all exhibit more potent inhibition of HDAC1 and HDAC2 than does CI-994, a class I HDACi (HDAC1, 2, 3) that had previously been reported to have prosynaptic effects ${ }^{22}$ (Figure 1, Table 1). Since the Rodin compounds also feature a foot pocket group as a key structural feature, we also profiled Cpd-60, ${ }^{20,25,27}$ a very potent inhibitor of HDAC1 and HDAC2, which has been reported to show effects on mood and behavior at relatively high doses $\left(45 \mathrm{mg} / \mathrm{kg}\right.$, ip). ${ }^{45}$ Both CI- $994^{17}$ and Cpd- $60^{25}$ have demonstrated safety and tolerability issues reported at doses where the CNS efficacy has been reported. The key differentiating profile of the 3-amino-pyridine-2-urea compounds was confirmed in HDAC co-repressor complex activity assays: Rodin-A, Rodin-B, Rodin-C, and Rodin-D primarily inhibit only the CoREST complex activity (Table 2, Figure 2). This is in contrast to CI-994, which inhibits the activity of the CoREST, NuRD, and NCoR complexes but not Sin3, as had been shown previously in the Bantscheff et al. chemoproteomics studies. ${ }^{21,30}$ The co-IP assay also confirmed the earlier findings that SAHA inhibits all the studied HDAC complexes. By adding a foot pocket to CI-994, Cpd-60 gains additional complex selectivity, targeting the CoREST and NCoR complexes. It is interesting to note that Cpd-60 shows inhibition of the NCoR complex, which contains only HDAC3, despite a high degree of selectivity for HDAC1 (>320-fold) and HDAC2 (>80-fold) over HDAC3 in recombinant enzymatic assays (Table 1). This suggests that recombinant enzymatic assays are not a good surrogate for the cellular context where HDACs are involved in multiprotein complexes. The comparison of binding poses of Rodin-A (Figure 1B,C) with $\mathrm{Cpd}-60^{27}$ does not offer any apparent explanation for differences in complex selectivity. While protein crystal structures of HDAC3/SMRT (NCoR) ${ }^{46}$ and HDAC1/ MTA1 (NuRD $)^{47}$ have been published, to the best of our knowledge there are no known ligand bound cocrystal structures of any HDAC multiprotein complexes. Future work in the structure of the HDAC-CoREST co-repressor complex would help elucidate reasons for the observed CoREST complex selectivity profile of these novel molecules. The high level of HDAC-CoREST co-repressor complex selectivity that we observed for the series of 3-amino-pyridine2-urea compounds toward the tested HDAC complexes is unprecedented.

The in vitro safety profiling of the CoREST selective compounds shows they are clearly differentiated from known prosynaptic HDACi like CI-994. The series of Rodin compounds all exhibit significantly improved in vitro hematological safety relative to the class I selective CI-994, despite the fact that they are more potent inhibitors of HDAC1 and HDAC2 activity than CI-994 (Table 1) and equally or more potent when associated with CoREST (Table 2). The hematological effects of Rodin compounds in vitro were mild compared to the severe effects of the class I selective HDACi CI-994 on both the myeloid and erythroid progenitor cells at the same concentrations after 14 days in culture (Table 3). This data suggests that the more complex-selective HDACi will have an improved hematological profile in humans. ${ }^{35}$ Whether the inhibition of the additional complexes is responsible for the additional toxicity is unknown. Cpd-60, which inhibits only CoREST and NCoR, also shows severe hematological toxicity in vitro, similar to CI-994. However, Cpd-60 is also much more potent on HDAC1, HDAC2, and HDAC3 than Rodin compounds. The comparison between the Rodin series compounds and CI-994 suggests that the enhanced selectivity might play a role in the differentiated safety profile. Effects of complex selectivity are also suggested when comparing the effects of Rodin-A and CI-994 on global histone H3K9 acetylation in K562 cells treated at concentrations up to 100 $\mu \mathrm{M}$ (Figure 3). Rodin-A treated cells show a lower magnitude of effect despite the fact that the inhibitory potencies of both compounds toward the HDAC-CoREST complex are similar and Rodin-A is more potent toward HDAC1 and HDAC2. While saturation of effect may not have been reached in these experiments, the acetylation differential observed at these high concentrations in vitro should offer a fair estimation of what might be observed at therapeutically relevant doses. The lower magnitude of acetylation of $\mathrm{H} 3 \mathrm{~K} 9$ could be a consequence of complex selectivity or simply differences in acetylation profile, and this is currently under investigation.

Because of the similarity in CoREST IC $_{50}$ to CI-994, the representative CoREST selective compound Rodin-A was extensively profiled in vivo to interrogate the effects of CoREST complex selective HDACi treatment. Rodin-A was shown to dose-dependently increase dendritic spine density in mouse hippocampus (Figure 4) and functionally improve the impaired LTP in the 5xFAD transgenic mouse model of amyloid pathology (Figure 6) at similar doses to CI-994. Rodin-A treatment also caused the associated increase in both SV2A/PSD95 coincidence and TrkB phosphorylation (Figure 5). Importantly, the prosynaptic effects of Rodin-A were 
achieved at doses and exposures far below the NOAEL exposures identified in rats and dogs (Table 4). Although it is not ideal to compare across species, if we look at the efficacious and toxic doses of Rodin-A from different studies, we can obtain a general assessment of the safety margin for the compound. Based on the $1 \mathrm{mg} / \mathrm{kg}$ dose of Rodin-A administered daily for 14 days to WT mice that stimulated a $21 \%$ increase in total spine density (Figure 4), a projected human equivalent dose (HED) based on body surface area ${ }^{48}$ is $4.8 \mathrm{mg} / \mathrm{kg}$. The NOAEL in rats of $45 \mathrm{mg} / \mathrm{kg}$ correlates to a HED of $432 \mathrm{mg} / \mathrm{kg}$, and the NOAEL in dogs of $120 \mathrm{mg} / \mathrm{kg}$ projects a HED of $3888 \mathrm{mg} / \mathrm{kg}$. Thus, even when basing calculations on rat as the most sensitive species, the efficacious HED of $4.8 \mathrm{mg} / \mathrm{kg}$ provides a safety margin of 90 -fold for Rodin-A at the NOAEL of $45 \mathrm{mg} / \mathrm{kg}$.

As a point of comparison, a previous report on the toxicity of CI-994 in rats and dogs after 2 weeks of dosing showed principal signals in tissues with rapidly dividing cell populations (bone marrow, testes), with similar effects in rats and dogs. ${ }^{17}$ Rats were dosed daily at $1.5 \mathrm{mg} / \mathrm{kg}, 5 \mathrm{mg} / \mathrm{kg}$, and $15 \mathrm{mg} / \mathrm{kg}$ orally (exposures not reported), and dogs were given daily doses of $0.5 \mathrm{mg} / \mathrm{kg}, 2 \mathrm{mg} / \mathrm{kg}$, or $5 \mathrm{mg} / \mathrm{kg}$ (day 12 AUC of $9.91 \mathrm{ng} \cdot \mathrm{h} / \mathrm{mL}$ at $2 \mathrm{mg} / \mathrm{kg}$ in males). The dose-limiting toxicity was primarily bone marrow suppression, but nonreversible testicular effects were also observed (rat $5 \mathrm{mg} / \mathrm{kg}$, $\operatorname{dog} 2 \mathrm{mg} / \mathrm{kg}$ ). Using the $1 \mathrm{mg} / \mathrm{kg}$ dose of CI-994 to WT mice that stimulated a similar increase in total spine density $(29 \%$, Figure 4) to Rodin-A (21\%) after 14 days of dosing, the projected HED for CI-994 is also $4.8 \mathrm{mg} / \mathrm{kg}$. The reported NOAEL in dogs of $0.5 \mathrm{mg} / \mathrm{kg}$ translates to a HED of $16.2 \mathrm{mg} /$ $\mathrm{kg}\left(10 \mathrm{mg} / \mathrm{m}^{2}\right) .{ }^{17}$ The $16.2 \mathrm{mg} / \mathrm{kg}$ HED therefore correlates to a safety margin of 3.4-fold for CI-994. Thus, the CoREST selective Rodin-A has maintained the prosynaptic effects of CI994 while improving the safety margin from 3.4-fold to 90 -fold based on HED and NOAEL in the most sensitive species. This suggests that the prosynaptic efficacy has been dissociated from classic HDAC-related toxicity in this new series of compounds. The in vivo studies performed with Rodin-A also show that the predictive in vitro hematological safety assays (Table 3 ) translate well to in vivo rat and dog safety studies for this series of compounds.

Taken together, our data suggests that CoREST inhibition is sufficient to achieve prosynaptic effects and that the CoREST co-repressor complex is a key controller of synaptic growth and function, based on the exquisite selectivity of Rodin-A for CoREST over the Sin3, NCoR, and NuRD co-repressor complexes. Since we have not yet identified compounds that selectively inhibit Sin3, NCoR, or NuRD, we cannot say if selective inhibition of one of these HDAC co-repressor complexes will lead to prosynaptic benefits, nor can we say that selective inhibition of one of these other complexes will lead to an improved safety profile. It is also important to note that HDAC1 and HDAC2 are involved in more multiprotein complexes than just the four complexes that were investigated in this study. These include the less studied multiprotein MiDAC complex and complexes involving the proteins MIER1, MIER2, and MIER3. ${ }^{21,30}$ Since we did not evaluate experimentally the ability to inhibit any of these complexes, we cannot comment on whether the series of 3-amino-pyridine-2urea compounds inhibit these complexes or whether these complexes are involved in the prosynaptic or improved safety effects observed. Our data allow us to say that of the four HDAC complexes studied, inhibition of CoREST alone is sufficient for maintaining prosynaptic effects and can also result in an improved safety profile in vitro and in vivo.

Achieving improved hematological safety with compounds such as Rodin-A enables the application of HDACi to longterm dosing of patients. Thus, the novel, CoREST co-repressor complex-selective HDACi, Rodin-A, represents a promising new potential therapeutic in synaptic pathology driven neurologic disorders such as Alzheimer's disease. Further studies with this and related compounds, including compounds with different complex inhibition profiles, are ongoing and will be reported in due course.

\section{METHODS}

The data that support the findings reported in this paper are available upon reasonable request.

All animal studies were conducted in accordance with local guidelines for the humane treatment of animals and were approved by the local Ethics Committees.

Microdialysis (Brains-on-Line) experiments were conducted in accordance with protocols approved by the Institutional Animal Care and Use Committee of Brains On-Line, LLC. LTP, spine density, and PK (ChemPartner) experimental protocols were approved by the Institutional Animal Care and Use Committee of ChemPartner, Shanghai, China. Safety studies (rat, dog) were conducted at Charles River Massachusetts and were reviewed and approved by Charles River Laboratories Institutional Animal Care and Use Committee (IACUC).

CI-994 was purchased from Sigma-Aldrich (C0621 SIGMA). SAHA was purchased from Sigma-Aldrich (SML0061). Cpd-60 was synthesized according to literature procedures. ${ }^{20}$ For the synthesis of Rodin-A, Rodin-B, Rodin-C, and Rodin-D, see the Supporting Information.

Study Design. For all in vivo studies, pilot studies were utilized to determine the variability in the readout of interest, and this information was used to determine the appropriate sample size. Rules for stopping data collection, data inclusion/exclusion criteria, and handling of outliers is described in the respective experimental sections below, where applicable. The end points and number of replicates are also described.

The research objectives, research subjects, and experimental design are outlined in the respective sections for each experiment, where applicable. Details on the statistical analyses used are provided in the experimental design and data analysis description or in the figure or table legends containing the data.

Code Availability. Dendritic spine analysis was done using Afraxis ESP software (Afraxis Inc., San Diego, CA). Queries regarding access to the analysis software code should be addressed to Afraxis Inc.

Recombinant HDAC Isoform Biochemical Assay (Nanosyn). See Supporting Information.

Screening of HDAC Co-repressor Complex Inhibition via Activity Determination of Co-immunoprecipitated HDAC Complexes (OmicScouts, Inc.). Cell Culture and Extraction of Nuclear Proteins. K562 cells were obtained from ATCC (ATCC CCL-243) and cultured according to the manufacturer's recommendations. Cells were harvested by centrifugation and subsequently washed three times in phosphate buffered saline without calcium and magnesium (1000 rpm, $5 \mathrm{~min}$, room temperature). Cell pellets were frozen at $-80{ }^{\circ} \mathrm{C}$ until further use.

Screening of HDAC Co-repressor Complex Inhibition via Activity Determination of Co-immunoprecipitated HDAC Complexes. Nuclear protein extraction from K562 cell pellets and coimmunoprecipitation (Co-IP) directed against HDAC complexes were performed using Active Motif s Nuclear complex Co-IP kit (no. 54001). Reagents and conditions for the different HDAC complex Co-IPs are summarized in Table 5. The following antibodies have been used: LSD1 (C69G12) rabbit mAb (no. 2148, Cell Signaling Technology), mSin3A rabbit pABb (no. ab3479, abcam), HDAC3 rabbit pAb (np. ab7030, abcam), MTA3 (428C2a) sc-81325 mouse $\mathrm{mAb}$ (no. sc-81325, Santa Cruz Biotechnology). In brief, the extract 
Table 5. Co-repressor Complex Immunoprecipitation Parameters

\begin{tabular}{llcc} 
complex & antibody & antibody dilution & nuclear extract amount [mg] \\
CoREST & LSD1 & $1: 25$ & 0.7 \\
Sin3 & mSin3A & $1: 50$ & 0.7 \\
NCoR & HDAC3 & $1: 625$ & 3 \\
NuRD & MTA3 & $1: 5$ & 3 \\
\hline
\end{tabular}

has been incubated with the specific antibody overnight at $4{ }^{\circ} \mathrm{C}$ followed by incubation with $50 \mu \mathrm{L}$ of Protein G Agarose (no. 11243233001 , Sigma; $\left.1 \mathrm{~h}, 4{ }^{\circ} \mathrm{C}\right)$. One Co-IP ( $260 \mu \mathrm{L}$ total volume) was distributed into 10 wells $(20 \mu \mathrm{L}$ per well $)$ and incubated with the test compound at 9 concentrations; the 10th aliquot was incubated with $100 \mu \mathrm{M}$ SAHA as positive control. Two replicate Co-IP and activity assay procedures were performed per compound. HDAC activity was measured after $120 \mathrm{~min}$ compound incubation using Active Motif's Fluorescent HDAC Assay Kit according to the manufacturer's instructions. Fluorescence was read-out using a FLUOstar microplate reader (excitation wavelength $355 \mathrm{~nm}$, emission wavelength $460 \mathrm{~nm}$ ).

LC-MS/MS Based Identification of Co-immunoprecipitated Proteins. An aliquot of the Co-IPs directed against each HDAC complex was subjected to LC-MS/MS based protein identification to confirm the integrity of the co-immunoprecipitated HDAC complex and the absence of other HDAC complexes and their activities. To this end, bound proteins were eluted from the beads via incubation in LDS buffer for $5 \mathrm{~min}$ at $95{ }^{\circ} \mathrm{C}$. Eluted proteins were processed for quantitative proteomics using standard in-gel digestion procedure. ${ }^{49,50}$

Nanoflow LC-MS/MS analysis of peptide samples was performed on an UltiMate 3000 RSLCnano System (Thermo Scientific, Dreieich, Germany) coupled to a Q-Exactive Plus quadrupole orbitrap mass spectrometer (Thermo Scientific, Bremen, Germany). Peptides were delivered to a trap column $(100 \mu \mathrm{m}$ inner diameter $\times 2$ $\mathrm{cm}$, packed with 5- $\mu \mathrm{m}$ C18 resin (Reprosil GOLD, Dr. Maisch, Germany) at a flow rate of $5 \mu \mathrm{L} / \mathrm{min}$ for $10 \mathrm{~min}$ in $0.1 \%$ FA in HPLCgrade water. After loading and washing, peptides were transferred to an analytical column $(75 \mu \mathrm{m}$ ID $\times 55 \mathrm{~cm} \mathrm{C18}$ column; Reprosil GOLD, $3 \mu \mathrm{m}$, Dr. Maisch, Germany) and separated using a linear gradient of $51 \mathrm{~min}$ ramping from $4 \%$ to $32 \%$ solvent B (0.1\% FA, $5 \%$ DMSO in ACN) at a flow rate of $300 \mathrm{~nL} / \mathrm{min} ; 5 \%(\mathrm{v} / \mathrm{v})$ DMSO was used in solvents A (0.1\% FA, 5\% DMSO in HPLC-grad water) and B to boost the nanoelectrospray response. Peptides were ionized using a $2.2 \mathrm{kV}$ electrospray voltage and a capillary temperature of $275^{\circ} \mathrm{C}$. The mass spectrometer was operated in data-dependent acquisition mode, automatically switching between MS and MS2 scans. Full-scan MS spectra $(m / z 360-1300)$ were acquired in the Orbitrap at 70000 $(\mathrm{m} / z 200)$ resolution with an automatic gain control (AGC) target value of $3 \mathrm{e} 6$. Fragment mass (MS2) spectra were generated for up to 20 precursors with a normalized collision energy of $28 \%$ using higher energy collision-induced dissociation (HCD). The fixed first mass was set to $100 \mathrm{~m} / z$ for fragment mass spectra, and fragment ions were read out in the Orbitrap mass analyzer at a resolving power of 17500 at $m / z 200$. The isolation window was set to $1.7 \mathrm{Th}$, and a MS2 AGC target value of 1 e5 was used. Sequenced precursor ions were dynamically excluded for $35 \mathrm{~s}$.

Data processing and peptide and protein identification and quantification was performed using MaxQuant (version 1.5.3.8) (including its built-in iBAQ calculations). ${ }^{51}$ Briefly, raw MS data were processed by MaxQuant for peak detection and quantification. MS/ MS spectra were searched against the current version of the human UniProt database (download date 21.08.2017) supplemented with common contaminants using the Andromeda search engine with the following search parameters: full tryptic specificity, up to two missed cleavage sites, carbamidomethylation of cysteine residues set as a fixed modification, and N-terminal protein acetylation and methionine oxidation as variable modifications. Mass spectra were recalibrated within MaxQuant (first search, $20 \mathrm{ppm}$ precursor tolerance) and subsequently researched with a mass tolerance of $6 \mathrm{ppm}$. Fragment ion mass tolerance was set to $20 \mathrm{ppm}$. Search results were filtered to a maximum false discovery rate (FDR) of $1 \%$ for proteins and $1 \%$ for peptide spectrum matches, and a minimum peptide length of at least 7 amino acids was required.

Effects of Rodin-A, Rodin-B, Rodin-C, Rodin-D, and Cl-994 on Human Myeloid and Erythroid Progenitors Using Colony Forming Cell Assays (ReachBio). Compounds were tested to evaluate the potential effects on human erythroid and myeloid progenitors using colony forming cell assays. Clonogenic progenitors of human erythroid (CFU-E, BFU-E), granulocyte-monocyte (CFU$\mathrm{GM}$ ), and multipotential (CFU-GEMM) lineages were assessed in a semisolid methylcellulose-based media formulation containing recombinant human interleukin 3 (rhIL-3, $10 \mathrm{ng} / \mathrm{mL}$ ), recombinant human granulocyte-macrophage colony-stimulating factor (rhGMCSF, $10 \mathrm{ng} / \mathrm{mL}$ ), recombinant human stem cell factor (rhSCF, 50 $\mathrm{ng} / \mathrm{mL}$ ) and erythropoietin (Epo, $3 \mathrm{U} / \mathrm{mL}$ ).

Cells. Normal human bone marrow light density cells derived from normal bone marrow (NorCal Biologics, California) and qualified at ReachBio were stored in the gaseous phase of liquid nitrogen $(-152$ ${ }^{\circ} \mathrm{C}$ ) until required for the assay. On the day of the experiment, the cells were thawed rapidly, the contents of each vial was diluted in 10 $\mathrm{mL}$ of Iscove's modified Dulbecco's medium containing $10 \%$ fetal bovine serum (IMDM $+10 \%$ FBS) and washed by centrifugation (approximately $1200 \mathrm{rpm}$ for $10 \mathrm{~min}$, room temperature). The supernatant was discarded, and the cell pellets resuspended in a known volume of IMDM $+10 \%$ FBS. A cell count (3\% glacial acetic acid) and viability assessment (trypan blue exclusion test) was performed for the bone marrow sample.

Compounds. On the day of the experiment, the compounds were dissolved in DMSO to a stock concentration of $10 \mathrm{mM}$. Serial dilutions were prepared from the stock concentration to achieve concentrations of 2 and $0.4 \mathrm{mM}$. When added to the methylcellulosebased media at 1:1000 (v/v), the final test concentrations of 10,2 , and $0.4 \mu \mathrm{M}$ were achieved. Additionally, 5-FU was evaluated at 1.0, 0.1 , and $0.01 \mu \mathrm{g} / \mathrm{mL}$.

Method Summary. Clonogenic progenitors of the human erythroid (CFU-E and BFU-E) and myeloid (CFU-GM) lineages were set up in the methylcellulose-based media formulations described above. All compounds were added to the medium to give the final desired concentrations (10,2, and $0.4 \mu \mathrm{M})$. 5-Fluorouracil (Sigma-Aldrich) was used as a positive control for progenitor proliferation (inhibition of colony growth) and was introduced to the human bone marrow cultures at $1.0,0.1$, and $0.01 \mu \mathrm{g} / \mathrm{mL}$. Solvent control cultures (containing no compound but $0.1 \% \mathrm{DMSO}$ ) as well as standard controls (containing no compound and no DMSO) were also initiated. Human myeloid and erythroid progenitor assays were initiated at $2.0 \times 10^{4}$ cells per culture. Following 14 days in culture, myeloid and erythroid colonies were assessed microscopically and scored by trained personnel. The colonies were divided into the following categories based on size and morphology: CFU-E, BFU-E, CFU-GM, and CFU-GEMM.

Statistical Analyses of CFC Numbers. The mean \pm SEM of three replicate cultures was calculated for progenitors of each category (CFU-E, BFU-E, etc.). Two-tailed $t$ tests were performed to assess if there was a difference in the number of colonies generated between solvent control and treated cultures. Due to the potential subjectivity of colony enumeration, a $p$ value of less than 0.01 is deemed significant. To calculate the concentration of $50 \%$ inhibition of colony growth $\left(\mathrm{IC}_{50}\right)$ for each compound, a dose response curve was generated plotting the log of the compound concentration versus the percentage of control colony growth using XLfit software (IDBS). The concentration of $50 \%$ inhibition of colony growth $\left(\mathrm{IC}_{50}\right)$ was calculated based on the sigmoid curve fit using dose-response, onesite model formula: $y=A+\left[(B-A) /\left(1+(C / x)^{D}\right)\right]$, where $A=$ the initial value (baseline response), $B=$ maximum response, $C=$ center (drug concentration that provokes a response halfway between $\mathrm{A}$ and B), and $D=$ slope of the curve at midpoint. Further plots and additional dose response curves were generated using GraphPad Prism 7.0. 
Morphological Assessment of Colonies. Photographs were taken of representative hematopoietic progenitor-derived colonies from various lineages, illustrating colonies in the presence of the solvent control as well as colonies in the presence of the test compounds.

Erythroid (CFU-E and BFU-E), myeloid (CFU-GM), and multipotential (CFU-GEMM) colony enumeration was performed by trained personnel. The distribution of colony types as well as general colony and cellular morphology was analyzed. For statistical analysis, colony numbers in compound treated cultures were compared to the solvent control cultures. 5-FU was used as a positive control for toxicity in these assays, and the inhibitory effects obtained for this compound were exactly as expected. The experiment was used to evaluate the potential effect of test compounds on human erythroid and myeloid progenitor proliferation in a methylcellulose-based medium. The $\mathrm{IC}_{50}$ values were calculated from XLfit. Dose response curves for erythroid and myeloid toxicity were generated by XLfit. Finally, nonlinear regression curve fitting and $\mathrm{IC}_{50}$ values $\pm 95 \% \mathrm{CI}$, were calculated by Prism 7.0.

Measuring the Effects of Rodin-A and $\mathrm{Cl}-994$ on Histone Acetylation. K562 cells were purchased from ATCC (Virginia, USA) and stored in liquid nitrogen until use (cultured for 10 days after thaw). K562 cells were cultured in IMDM medium plus $10 \%$ FBS and pen/strep, in a cell culture incubator at $37^{\circ} \mathrm{C}$ with $5 \% \mathrm{CO}_{2}$. Anti-Ac-H3K9 rabbit mAb (no. 9649) and anti-H3 mouse mAb (no. 3638) were purchased from Cell Signaling Technology. Anti-rabbit IgG IRDye $680 \mathrm{RD}$ and anti-mouse IgG IRDye $800 \mathrm{CW}$ secondary antibodies were purchased from LI-COR. Bis-Tris gel (12\%) and nitrocellulose membrane were purchased from Thermo Fisher Scientific. For the assays, $3 \times 10^{5}$ cells/well of K562 cells in $1 \mathrm{~mL}$ of complete culture medium was seeded to the wells of 24-well plates overnight. The cells were treated with compounds in triplicate (starting at $33.3 \mu \mathrm{M}, 10$-doses with 3-fold dilution) for $24 \mathrm{~h}$. Cells treated with $5 \mu \mathrm{M}$ SAHA and $10 \mu \mathrm{M}$ TSA were used as the positive control. Cells treated with $0.1 \%$ DMSO were used as the negative control. After treatment, the K562 cells were washed once with PBS and lysed with $100 \mu \mathrm{L}$ of $1 \times$ SDS sample buffer containing $50 \mathrm{mM}$ DTT. The lysate samples were sonicated and then heated at $90{ }^{\circ} \mathrm{C}$ for $5 \mathrm{~min}$. Cell lysate samples $(13 \mu \mathrm{L})$ were subjected to SDS-PAGE with $12 \%$ Bis-Tris gel and transferred onto nitrocellulose membrane by iBlot dry blotting system. The membrane was blocked with $3 \%$ nonfat milk for $1 \mathrm{~h}$ and probed with anti-Ac-H3K9 and anti-H3 antibodies. Anti-rabbit IgG IRDye 680RD and anti-mouse IgG IRDye $800 \mathrm{CW}$ secondary antibodies were used to detect the primary antibodies. The membranes were scanned with LI-COR Odyssey Fc Imaging System. The specific bands of interest were quantified by LI-COR Image Studio Lite software. Change in acetylation status of H3K9 was determined by normalizing Ac-H3K9 bands to $\mathrm{H} 3$ bands (Figure 2C, Figure $\mathrm{S} 1$ ). The percent acetylated $\mathrm{H} 3 \mathrm{~K} 9$ relative control $\mathrm{EC}_{50}$ curves were plotted, and $\mathrm{EC}_{50}$ values were calculated using the GraphPad Prism 7 program based on a 4-parameter sigmoidal dose-response equation.

Evaluation of the Free Drug Concentration of Rodin-A in Mouse Hippocampus by MetaQuant Microdialysis and Plasma Concentration. The biotechnical and bioanalytical experiments described in the present report were performed at Brains OnLine, LLC (South San Francisco, USA).

Animals. Eight adult male C57Bl/6 mice $(20-30 \mathrm{~g})$ were used for this study. Upon arrival, the animals were group-housed in plastic cages on a $12 / 12 \mathrm{~h}$ light/dark cycle. Animals had access to food and water ad libitum. Experiments were conducted in accordance with protocols approved by the Institutional Animal Care and Use Committee of Brains On-Line, LLC.

Test Substance and Formulation. Test compound (Rodin-A) was prepared in $20 \% \mathrm{HP} \beta \mathrm{CD}$ in sterile water and sonicated at room temperature for $90 \mathrm{~min}$. Solutions were prepared fresh daily for dosing.

Surgery. Mice were anesthetized using isoflurane $(2 \%, 800 \mathrm{~mL} /$ min $\mathrm{O}_{2}$ ). Bupivacaine/epinephrine was used for local anesthesia, and carprofen was used for peri-/postoperative analgesia. First, a jugular vein (JV) cannula was implanted for serial blood collection
(BrainLink, The Netherlands). Then, the animals were placed in a stereotaxic frame (Kopf Instruments, USA) and a MetaQuant (MQ) microdialysis probe $(4 \mathrm{~mm}$ PAN membrane, BrainLink, The Netherlands) was implanted into the right hippocampus. A second microdialysis probe $(3 \mathrm{~mm}$ PEE membrane, BrainLink, The Netherlands) was inserted into the left hippocampus. Coordinates for the tips of the probes into the hippocampus were as follows: anterior-posterior $(\mathrm{AP})=-3.1 \mathrm{~mm}$ from bregma, lateral $(\mathrm{L})= \pm 2.8$ $\mathrm{mm}$ from midline, and ventral $(\mathrm{V})=-4.5 \mathrm{~mm}$ from dura; the toothbar set at $0.0 \mathrm{~mm}$. After surgery, animals were housed individually in cages and provided food and water ad libitum.

Experiments. Experiments were performed 1 day after surgery. On experimental day 1 , the MetaQuant microdialysis probe was connected with flexible PEEK tubing to a microperfusion pump (Harvard PHD 2000 Syringe pump, Holliston, MA). Microdialysis probes were perfused with aCSF containing $147 \mathrm{mM} \mathrm{NaCl}, 3.0 \mathrm{mM}$ $\mathrm{KCl}, 1.2 \mathrm{mM} \mathrm{CaCl}_{2}, 1.2 \mathrm{mM} \mathrm{MgCl}_{2}+0.2 \% \beta$-CD, at a slow flow rate of $0.15 \mu \mathrm{L} / \mathrm{min}$ and a carrier flow (UP $+0.2 \% \beta$-CD) at a rate of 0.8 $\mu \mathrm{L} / \mathrm{min}$. Microdialysis samples were collected for 30 min periods by an automated fraction collector (820 Microsampler, Univentor, Malta) into $300 \mu \mathrm{L}$ polypropylene minivials. After stabilization, one baseline sample was collected, and test compounds were given PO. Samples were collected for an additional $9 \mathrm{~h}$. All the samples were stored at $-80{ }^{\circ} \mathrm{C}$ awaiting analysis by Brains On-Line. Blood samples were collected via the JV cannula at $0,30,60,120,360$, and $540 \mathrm{~min}$ after dosing into EDTA anticoagulant vials ( $\sim 25 \mu \mathrm{L}$ blood/sample). Plasma was harvested within $15 \mathrm{~min}$ after collection and aliquoted $(\sim 10 \mu \mathrm{L} /$ sample $)$ into a separate vial and stored at $-80{ }^{\circ} \mathrm{C}$ awaiting analysis by Brains On-Line. On the following day (day 2), the push/ pull microdialysis probes were connected with FEP tubing to a microperfusion pump (Harvard PHD 2000 Syringe pump, Holliston, MA or similar). Microdialysis probes were perfused with aCSF containing $147 \mathrm{mM} \mathrm{NaCl}, 3.0 \mathrm{mM} \mathrm{KCl}, 1.2 \mathrm{mM} \mathrm{CaCl}_{2}$ and $1.2 \mathrm{mM}$ $\mathrm{MgCl}_{2}$, and $0.15 \% \mathrm{BSA}$ at a flow rate of $0.75 \mu \mathrm{L} / \mathrm{min}$. Microdialysis samples were collected for 60 min periods by an automated fraction collector ( 820 Microsampler, Univentor, Malta) into polypropylene $(300 \mu \mathrm{L})$ minivials. Samples were collected for a total of $8 \mathrm{~h}$ after dosing. At the end of day 2 of dialysis, mice were euthanized and brain was collected for verification of probe placement by Brains On-Line. $\mathrm{Push} /$ pull dialysis samples were stored at $-80{ }^{\circ} \mathrm{C}$ before shipping.

Bioanalysis. Concentrations of Rodin- $\mathrm{A}$ in dialysates and plasma were determined by HPLC coupled to a tandem mass spectrometer (LC/MS/MS).

Quantification of Rodin-A. Plasma samples were first mixed for protein precipitation with a solution of acetonitrile/ultrapure water $(80: 20)$. After $5 \mathrm{~min}$ incubation at room temperature, the samples were centrifuged for $5 \mathrm{~min}\left(13000 \mathrm{rpm}, 4{ }^{\circ} \mathrm{C}\right)$ and the supernatant was diluted 10-fold in ultrapure water/acetonitrile (80:20). Dialysate samples and diluted plasma supernatants were injected $(5 \mu \mathrm{L})$ into an Infinity 1290 LC system (Agilent, USA) by an automated sample injector (SIL-20AD, Shimadzu, Japan). Analytes were separated by liquid chromatography using a linear gradient of mobile phase $\mathrm{B}$ at a flow rate of $0.300 \mathrm{~mL} / \mathrm{min}$ on a reversed phase Phenomenex Luna C18(2)-HST column $(3.0 \mathrm{~mm} \times 100 \mathrm{~mm}, 2.5 \mu \mathrm{m}$ particle size; Phenomenex, USA) held at a temperature of $35^{\circ} \mathrm{C}$. Mobile phase A consisted of $\mathrm{UP}_{2} \mathrm{O}$ with $5 \mathrm{mM}$ ammonium acetate. Mobile phase $\mathrm{B}$ was $\mathrm{MeOH}$ with $5 \mathrm{mM}$ ammonium acetate. Acquisitions were achieved in positive ionization mode using a QTrap 5500 (Applied Biosystems, USA) equipped with a Turbo Ion Spray interface. The ion spray voltage was set at $5.0 \mathrm{kV}$, and the probe temperature was $500{ }^{\circ} \mathrm{C}$. The collision gas (nitrogen) pressure was kept at the Medium setting level. The following MRM transitions were used for quantification: $353.3 / 218.0$ for Rodin-A. Data were calibrated and quantified using the Analyst data system (Applied Biosystems, version 1.5.2).

Hippocampal Dendritic Spine Density Analysis. Research Objectives. To measure the effects on dendritic spines in hippocampus after oral dosing of compound daily for $3,7,10$, or 14 days.

Research Subjects. Male C57BL/6J mice (from Shanghai Lingchang Biotech, Shanghai, China) were dosed orally with CI- 
994 (daily with 1 and $3 \mathrm{mg} / \mathrm{kg}$ for 3 to 14 days, $n=5$ per group) or with Rodin-A (daily with 1,3 , and $6 \mathrm{mg} / \mathrm{kg}$, for 3, 7, 10, and 14 days, $n=7$ per group) or vehicle ( $20 \% \mathrm{HP} \beta \mathrm{CD}$, daily for $3,7,10$, and 14 days, $n=5$ or 7 per group) at ChemPartner, Shanghai, China. Male C57BL/6J mice were dosed orally with CI-994 (daily with 0.3 and 3 $\mathrm{mg} / \mathrm{kg}$ for 14 days $)$ or vehicle $\left(0.5 \% \mathrm{MC}+0.1 \%\right.$ Tween 80 in $\mathrm{dd}_{2} \mathrm{O}$, daily for 14 days, $n=7$ per group). Animals were sacrificed $24 \mathrm{~h}$ after the last dose of CI-994 and 24 h, 3 days, and 7 days after last dose of Rodin-A and vehicle. Ballistic dye labeling was performed according to protocols developed by Afraxis to label target neurons (Afraxis, SanDiego, CA). ${ }^{52}$ Laser-scanning confocal microscopy (Olympus FV1000) was performed using a $63 \times$ objective (1.42 NA) to scan individually labeled neurons at high resolution $(0.103 \times 0.103 \times 0.33$ $\mu \mathrm{m}^{3}$ voxels). Target neurons were identified in the brain region of interest by anatomical location and cell morphology. A minimum of 5 samples per mouse were measured for each segment. Blind deconvolution was applied to raw three-dimensional digital images, which were then analyzed for spine density and morphology by trained analysts. Individual spines were measured manually for (a) head diameter, (b) length, and (c) neck thickness. Each dendrite was analyzed by 3 (on average) independent analysts. Automated image assignment software distributed images to analysts in a randomized manner and ensured that each analyst performed measurements of near equal numbers of dendrites per group. Analysts were blinded to all experimental conditions (including treatment, brain region, and cell type).

Statistical analysis of interanalyst variability for each dendrite was examined online and used to eliminate dendrites that did not meet interanalyst reliability criteria. For spine density and spine morphological classification, data across analysts were averaged to report data for each dendrite. Data for each dendrite were then averaged to report data for each mouse.

Means and SEM for spine density were calculated using animal's individual values. A one-way ANOVA was performed followed by a Dunnett's post hoc analysis.

Immunofluorescence and Microscopy Measurements of SV2A, pTrkB, and PSD-95. Research Objectives. To measure SV2A, pTrkB, and PSD-95 in brain slices from mice dosed orally with compound.

Research Subjects. From male C57BL/6J mice, $20 \mu \mathrm{m}$ slices from the brain region of interest were incubated for $24 \mathrm{~h}\left(4{ }^{\circ} \mathrm{C}\right)$ in blocking solution (0.1 M PB, 4\% bovine serum albumin, 0.3\% Triton-X-100) with the following primary antibodies: rabbit anti-SV2A (1:500; Abcam ab32942), mouse anti-PSD95 (1:1000, Affinity Bioreagents, no. MA1-045), rabbit anti-phosphorylated Trk (Tyr490; 1:200; Cell Signaling no. 9141). Sections were incubated for $1 \mathrm{~h}$ (RT) in secondary antisera with Alexa594 anti-rabbit IgG and Alexa488 antimouse IgG (Invitrogen). Although anti-pTrk ${ }^{\mathrm{Y} 90}$ recognizes a site conserved across TrkA, $-\mathrm{B}$, and $-\mathrm{C}$, TrkB is predominantly expressed by hippocampal neurons, and both $\mathrm{TrkC}$ and TrkA are therefore unlikely to contribute to results. Super-resolution laser-scanning confocal microscopy (Zeiss LSM880, Airyscan) $)^{52,53}$ was performed using a $63 \times$ objective $(1.4 \mathrm{NA})$ to scan regions of interest $(20 \times 20 \times$ $5 \mu \mathrm{m}^{3}, x y z$ ) at high resolution (scan resolution $=0.07 \mu \mathrm{m} /$ pixel; axial resolution $=0.07 \mu \mathrm{m} /$ focal step). Target laminae were identified in the brain region of interest by epifluorescence navigation (DAPI) using anatomical landmarks. Microscopy was performed blind to experimental conditions. A minimum of 5 mice were tested in each experimental condition. A minimum of 5 samples per mouse were measured for each target lamina. Micrographs were analyzed using image segmentation analysis based on established protocols. ${ }^{53,54}$ Intensity normalization to a target background level (15\% of maximum) was performed on image subsections $\left(5 \times 5 \times 1 \mu \mathrm{m}^{3}\right)$ to standardize object quantification across sections and batches of tissue. A one-way ANOVA was performed followed by a Dunnett's post hoc analysis.

Measurement of LTP in 5xFAD Mice. Research Objectives. To measure the effects on long-term potentiation upon daily dosing for 14 days to mice with cognitive deficits.
Research Subjects. The effects of Rodin-A were tested in the $5 \mathrm{xFAD}$ mouse model of AD on the properties of LTP at the Schaffer collateral-CA1 hippocampal synaptic layer in 9-12 month old mice (C57BL/6J background strain). Animals were dosed once daily by oral gavage for 14 days. Animals were sacrificed and hippocampal brain slices $(350 \mu \mathrm{m})$ were cut on the ice-cold stage of a vibrating tissue slicer. The slices were maintained in oxygenated artificial cerebrospinal fluid (aCSF, $124 \mathrm{mM} \mathrm{NaCl}, 3 \mathrm{mM} \mathrm{KCl}, 1.2 \mathrm{mM}$ $\mathrm{NaH}_{2} \mathrm{PO}_{4}, 26 \mathrm{mM} \mathrm{NaHCO}, 2.4 \mathrm{mM} \mathrm{CaCl} 2,2 \mathrm{mM} \mathrm{MgCl}, 10 \mathrm{mM}$ glucose, $\mathrm{pH}$ 7.4) at room temperature for at least $1 \mathrm{~h}$, and then slices were transferred to the multielectrode recording chamber and constantly perfused with oxygenated aCSF at $30^{\circ} \mathrm{C}$ for $0.5 \mathrm{~h}$ before recording. Electrophysiology was performed with a MED-PG515A 16 electrode array. The basal synaptic transmission was characterized by monitoring the fEPSP slope every second for $30 \mathrm{~min}$ before the theta burst stimulus (TBS) was applied, and the $10 \%-90 \%$ slope of input/ output (I/O) curves of the field excitatory postsynaptic potential (fEPSP) was determined. The stimulus current was adjusted so that fEPSP stabilized at $50 \%$ of maximum. LTP was induced by theta burst stimulus (TBS, 10 bursts with $200 \mathrm{~ms}$ interburst interval, each burst consisting of 4 pulses at $100 \mathrm{~Hz}$, delivered at $1.6 \times$ stimulation intensity of the baseline stimulation). Test stimulation resumed immediately after the TBS, and recording of the evoked fEPSP responses was monitored for the next $60 \mathrm{~min}$. The plateau of the last $10 \mathrm{~min}$ fEPSP slope post-TBS was considered the LTP response. All LTP measurements were performed blinded to treatment. Occasionally, several LTP measures were made in a single slice and/or from multiple slices taken from a single animal; in all cases LTP values were averaged per animal before being used, and the $n$ is the number of animals analyzed per arm. For all experiments, statistical analysis was by ANOVA with post hoc Holm-Sidak analysis corrected for multiple comparisons using statistical hypothesis testing (GraphPad Prism 7 software).

In Vivo 14 Day Safety Evaluation in Rat and Dog. Rat. The objective of this study was to determine the potential toxicity of Rodin-A when given by gavage once daily for 14 days to male Sprague-Dawley rats. In addition, the toxicokinetic characteristics of Rodin-A were determined using a nonvalidated bioanalytical method. In total, 20 male rats were dosed with either Rodin-A (30, 45, or 60 $\mathrm{mg} / \mathrm{kg} /$ day or vehicle $(0.5 \%$ methylcellulose $/ 0.1 \%$ Tween 80 in RODI (reverse osmosis deionized) water); $n=12$ for safety studies and $n=8$ for toxicokinetic analysis). End points in the study consisted of mortality checks, clinical observations, body weight (weekly) and food consumption (daily) measurements, clinical pathology (hematology and clinical chemistry), bone marrow smear evaluations, toxicokinetic evaluation, and anatomical pathology evaluations consisting of macroscopic observations, organ weights, and microscopic evaluations.

Dog. The objective of this study was to determine the potential toxicity of Rodin-A when given by gavage once daily for 14 days to male beagle dogs. In addition, the toxicokinetic characteristics of Rodin-A were determined using a nonvalidated bioanalytical method. Naive beagle dogs (15 male animals; $7.8-11.8 \mathrm{~kg}$ and $12-13$ months old at the time of dosing) were assigned to dose groups and dosed with Rodin-A $(45,60$, or $120 \mathrm{mg} / \mathrm{kg} /$ day $)$ or vehicle $(0.5 \%$ methylcellulose/0.1\% Tween 80 in RODI water. End points in the study consisted of mortality checks, clinical observations, body weight (weekly) and food consumption (daily) measurements, clinical pathology (hematology and clinical chemistry), bone marrow smear evaluations, toxicokinetic evaluation, and anatomical pathology evaluations consisting of macroscopic observations, organ weights, and microscopic evaluations.

\section{ASSOCIATED CONTENT}

\section{S Supporting Information}

The Supporting Information is available free of charge on the ACS Publications website at DOI: 10.1021/acschemneuro.8b00620. 
Experimental procedures for the synthesis of Rodin-A, Rodin-B, Rodin- $\mathrm{C}$, and Rodin-D, experimental details and procedure for recombinant HDAC isoform biochemical assays, data collection and processing statistics for cocrystal structure of Rodin-A bound to HDAC2, experimental procedure and inhibition data for LSD1 and LSD1/CoREST recombinant enzymatic assays, experimental procedure for pharmacokinetic studies, full Western blots of acetylation at histone 3, position lysine 9 for Rodin-A and CI-994, hippocampal dendritic spine density following 14 days of dosing with Rodin-A, pharmacokinetic data for CI-994 and Rodin-A in mice, and pharmacokinetic data from microdialysis experiments with Rodin-A in mice (PDF)

\section{AUTHOR INFORMATION}

\section{Corresponding Author}

*E-mail: magnus@rodintherapeutics.com.

\section{ORCID $\odot$}

Nathan O. Fuller: 0000-0003-2149-5412

\section{Present Addresses}

${ }^{\dagger}$ M.S.Q.: Takeda Pharmaceuticals, 35 Landsdowne St., Cambridge, MA 02139.

†.D.M.: Takeda, 75 Sidney St., Cambridge, MA 02139.

\section{Author Contributions}

N.O.F. designed compounds and chemistry strategy, analyzed data, and wrote the paper. B.A.L., M.C.H., T.D.M., and M.S.Q. designed and coordinated in vitro and in vivo experiments and analyzed data. A.P. analyzed data and wrote the paper. M.I. contributed to overall strategy and experimental design and wrote the paper.

\section{Funding}

Part of this work was supported by grants from the NIH (SBIR Grant 1R43AG048651-01A1), Michael J. Fox Foundation (Grant 11581), and the Alzheimer's Drug Discovery Foundation (Grant No. 20150504.02).

\section{Notes}

The authors declare the following competing financial interest(s): The authors are, or were, employees of Rodin Therapeutics, Inc., and are stockholders in the company.

\section{ACKNOWLEDGMENTS}

We thank Hannes Hahne and colleagues at OmicScouts, Christopher Rex and colleagues at Afraxis, Yingtao Tong, Dongfeng Hou, and colleagues at ChemPartner, Jianghong $\mathrm{Wu}$, Wei Xiao, and colleagues at Reaction Biology, and Emer Clarke and colleagues at ReachBio for experimental support. We thank Stefan Steinbacher and Peter Reinemer of Proteros for the work on the Rodin-A cocrystal structure. We thank John A. Lowe III of JL3 Pharma for useful discussions on medicinal chemistry.

\section{ABBREVIATIONS}

HDAC, histone deacetylase; CoREST, co-repressor of Repressor Element1 Silencing Transcription Factor; HDACi, histone deacetylase inhibitor; REST, repressor element-1 silencing transcription factor; NuRD, nucleosome remodeling and deacetylase; Sin3, switch-independent protein 3; SMRT, silencing mediator of retinoic acid and thyroid hormone receptor; NCoR, nuclear receptor co-repressor; LSD1, lysinespecific demethylase 1; CFU, colony forming unit; WT, wild- type; $\mathrm{HP} \beta \mathrm{CD}$, hydroxypropyl- $\beta$-cyclodextrin; SV2A, presynaptic vesicle glycoprotein 2A; PSD95, postsynaptic density protein 95; BDNF, brain-derived neurotrophic factor; TrkB, tropomyosin receptor kinase $\mathrm{B}$; pTrkB, phosphorylated tropomyosin receptor kinase $\mathrm{B}$; LTP, long-term potentiation; NOAEL, no-obsersved-adverse-effect level; AUC, area under the curve; HED, human equivalent dose

\section{REFERENCES}

(1) Coleman, P. D., and Yao, P. J. (2003) Synaptic slaughter in Alzheimer's disease. Neurobiol. Aging 24, 1023-1027.

(2) Imbriani, P., Schirinzi, T., Meringolo, M., Mercuri, N. B., and Pisani, A. (2018) Centrality of Early Synaptopathy in Parkinson's Disease. Front. Neurol. 9, 103.

(3) Masliah, E., Mallory, M., Alford, M., DeTeresa, R., Hansen, L. A., McKeel, D. W., Jr., and Morris, J. C. (2001) Altered expression of synaptic proteins occurs early during progression of Alzheimer's disease. Neurology 56, 127-129.

(4) Scheff, S. W., Neltner, J. H., and Nelson, P. T. (2014) Is synaptic loss a unique hallmark of Alzheimer's disease? Biochem. Pharmacol. 88, $517-528$.

(5) Terry, R. D., Masliah, E., Salmon, D. P., Butters, N., DeTeresa, R., Hill, R., Hansen, L. A., and Katzman, R. (1991) Physical basis of cognitive alterations in Alzheimer's disease: Synapse loss is the major correlate of cognitive impairment. Ann. Neurol. 30, 572-580.

(6) de Wilde, M. C., Overk, C. R., Sijben, J. W., and Masliah, E. (2016) Meta-analysis of synaptic pathology in Alzheimer's disease reveals selective molecular vesicle machinery vulnerability. Alzheimer's Dementia 12, 633-644.

(7) Scheff, S. W., Price, D. A., Ansari, M. A., Roberts, K. N., Schmitt, F. A., Ikonomovic, M. D., and Mufson, E. J. (2015) Synaptic change in the posterior cingulate gyrus in the progression of Alzheimer's disease. J. Alzheimer's Dis. 43, 1073-1090.

(8) de Ruijter, A. J. M., van Gennip, A. H., Caron, H. N., Kemp, S., and van Kuilenburg, A. B. P. (2003) Histone deacetylases (HDACs): characterization of the classical HDAC family. Biochem. J. 370, 737749.

(9) Guan, J.-S., Haggarty, S. J., Giacometti, E., Dannenberg, J.-H., Joseph, N., Gao, J., Nieland, T. J. F., Zhou, Y., Wang, X., Mazitschek, R., Bradner, J. E., DePinho, R. A., Jaenisch, R., and Tsai, L.-H. (2009) HDAC2 negatively regulates memory formation and synaptic plasticity. Nature 459, 55-60.

(10) Gräff, J., Rei, D., Guan, J.-S., Wang, W.-Y., Seo, J., Hennig, K. M., Nieland, T. J. F., Fass, D. M., Kao, P. F., Kahn, M., Su, S. C., Samiei, A., Joseph, N., Haggarty, S. J., Delalle, I., and Tsai, L.-H. (2012) An epigenetic blockade of cognitive functions in the neurodegenerating brain. Nature 483, 222-206.

(11) Penney, J., and Tsai, L.-H. (2014) Histone deacetylases in memory and cognition. Sci. Signaling 7, re12.

(12) Nativio, R., Donahue, G., Berson, A., Lan, Y., Amlie-Wolf, A., Tuzer, F., Toledo, J. B., Gosai, S. J., Gregory, B. D., Torres, C., Trojanowski, J. Q., Wang, L.-S., Johnson, F. B., Bonini, N. M., and Berger, S. L. (2018) Dysregulation of the epigenetic landscape of normal aging in Alzheimer's disease. Nat. Neurosci. 21, 497-505.

(13) Fischer, A., Sananbenesi, F., Wang, X., Dobbin, M., and Tsai, L.-H. (2007) Recovery of learning and memory is associated with chromatin remodeling. Nature 447, 178-182.

(14) Akhtar, M. W., Raingo, J., Nelson, E. D., Montgomery, R. L., Olson, E. N., Kavalali, E. T., and Monteggia, L. M. (2009) Histone deacetylases 1 and 2 form a developmental switch that controls excitatory synapse maturation and function. J. Neurosci. 29, 82888297.

(15) Kazantsev, A. G., and Thompson, L. M. (2008) Therapeutic application of histone deacetylases for central nervous system disorders. Nat. Rev. Drug Discovery 7, 854-868.

(16) Subramanian, S., Bates, S. E., Wright, J. J., Espinoza-Delgado, I., and Piekarz, R. L. (2010) Clinical toxicities of histone deacetylase inhibitors. Pharmaceuticals 3, 2751-2767. 
(17) Graziano, M. J., Pilcher, G. D., Walsh, K. M., Kasalil, O. B., and Radulovic, L. (1997) Preclinical toxicity of a new oral anticancer drug, CI-994 (Acetyldinaline), in rats and dogs. Invest. New Drugs 15, 295310.

(18) Gupta, P., Reid, R. C., Iyer, A., Sweet, M. J., and Fairlie, D. P. (2012) Towards Isozyme-Selective HDAC Inhibitors For Interrogating Disease. Curr. Top. Med. Chem. 12, 1479-1499.

(19) Wagner, F. F., Zhang, Y.-L., Fass, D. M., Joseph, N., Gale, J. P., Weïwer, M., McCarren, P., Fisher, S. L., Kaya, T., Zhao, W.-N., Reis, S. A., Hennig, K. M., Thomas, M., Lemercier, B. C., Lewis, M. C., Guan, J. S., Moyer, M. P., Scolnick, E., Haggarty, S. J., Tsai, L.-H., and Holson, E. B. (2015) Kinetically selective inhibitors of histone deacetylase 2 (HDAC2) as cognition enhancers. Chem. Sci. 6, 804815.

(20) Moradei, O. M., Mallais, T. C., Frechette, S., Paquin, I., Tessier, P. E., Leit, S. M., Fournel, M., Bonfils, C., Trachy-Bourget, M.-C., Liu, J., Yan, T. P., Lu, A.-H., Rahil, J., Wang, J., Lefebvre, S., Li, Z., Vaisburg, A. F., and Besterman, J. M. (2007) Novel aminophenyl benzamide-type histone deacetylase inhibitors with enhanced potency and selectivity. J. Med. Chem. 50, 5543-5546.

(21) Bantscheff, M., Hopf, C., Savitski, M. M., Dittmann, A., Grandi, P., Michon, A.-M., Schlegl, J., Abraham, Y., Becher, I., Bergamini, G., Boesche, M., Delling, M., Dümpelfeld, B., Eberhard, D., Huthmacher, C., Mathieson, T., Poeckel, D., Reader, V., Strunk, K., Sweetman, G., Kruse, U., Neubauer, G., Ramsden, N. G., and Drewes, G. (2011) Chemoproteomics profiling of HDAC inhibitors reveals selective targeting of HDAC complexes. Nat. Biotechnol. 29, 255-265.

(22) Gräff, J., Joseph, N. F., Horn, M. E., Samiei, A., Meng, J., Seo, J., Rei, D., Bero, A. W., Phan, T. X., Wagner, F., Holson, E., Xu, J., Sun, J., Neve, R. L., Mach, R. H., Haggarty, S. J., and Tsai, L.-H. (2014) Epigenetic priming of memory updating during reconsolidation to attenuate fear memories. Cell 156, 261-276.

(23) Ballas, N., Grunseich, C., Lu, D. D., Speh, J. C., and Mandel, G. (2005) REST and its corepressors mediate plasticity of neuronal gene chromatin throughout neurogenesis. Cell 121, 645-657.

(24) Abrajano, J. J., Qureshi, I. A., Gokhan, S., Zheng, D., Bergman, A., and Mehler, M. F. (2009) REST and CoREST modulate neuronal subtype specification, maturation, and maintenance. PLoS One 4, No. e7936.

(25) Methot, J. L., Chakravarty, P. K., Chenard, M., Close, J., Cruz, J. C., Dahlberg, W. K., Fleming, J., Hamblett, C. L., Hamill, J. E., Harrington, P., Harsch, A., Heidebrecht, R., Hughes, B., Jung, J., Kenific, C. M., Kral, A. M., Meinke, P. T., Middleton, R. E., Ozerova, N., Sloman, D. L., Stanton, M. G., Szewczak, A. A., Tyagarajan, S., Witter, D. J., Secrist, J. P., and Miller, T. A. (2008) Exploration of the internal cavity of histone deacetylase (HDAC) with selective HDAC1/HDAC2 inhibitors (SHI-1:2). Bioorg. Med. Chem. Lett. 18, 973-978.

(26) Bressi, J. C., Jennings, A. J., Skene, R., Wu, Y., Melkus, R., Jong, R. D., O'Connell, S., Grimshaw, C. E., Navre, M., and Gangloff, A. R. (2010) Exploration of the HDAC2 foot pocket: Synthesis and SAR of substituted N-(2-aminophenyl)benzamides. Bioorg. Med. Chem. Lett. 20, 3142-3145.

(27) Lauffer, B. E. L., Mintzer, R., Fong, R., Mukund, S., Tam, C., Zilberleyb, I., Flicke, B., Ritscher, A., Fedorowicz, G., Vallero, R., Ortwine, D. F., Gunzner, J., Modrusan, Z., Neumann, L., Koth, C. M., Lupardus, P. J., Kaminker, J. S., Heise, C. E., and Steiner, P. (2013) Histone deacetylase (HDAC) inhibitor kinetic rate constants correlate with cellular histone acetylation but not transcription and cell viability. J. Biol. Chem. 288, 26926-26943.

(28) Wagner, F. F., Weïwer, M., Steinbacher, S., Schomburg, A., Reinemer, P., Gale, J. P., Campbell, A. J., Fisher, S. L., Zhao, W.-N., Reis, S. A., Hennig, K. M., Thomas, M., Müller, P., Jefson, M. R., Fass, D. M., Haggarty, S. J., Zhang, Y.-L., and Holson, E. B. (2016) Kinetic and structural insights into the binding of histone deacetylase 1 and 2 (HDAC1,2) inhibitors. Bioorg. Med. Chem. 24, 4008-4015.

(29) Berger, M. R., Richter, H., Seelig, M. H., Eibl, J., and Schmähl, D. (1990) New cytostatics - more activity and less toxicity. Cancer Treat. Rev. 17, 143-154.
(30) Becher, I., Dittmann, A., Savitski, M. M., Hopf, C., Drewes, G., and Bantscheff, M. (2014) Chemoproteomics reveals time-dependent binding of histone deacetylase inhibitors to endogenous repressor complexes. ACS Chem. Biol. 9, 1736-1746.

(31) Millard, C. J., Watson, P. J., Fairall, L., and Schwabe, J. W. R. (2017) Targeting Class I Histone Deacetylases in a "Complex" Environment. Trends Pharmacol. Sci. 38, 363-377.

(32) Robertson, J. C., Hurley, N. C., Tortorici, M., Ciossani, G., Borrello, M. T., Vellore, N. A., Ganesan, A., Mattevi, A., and Baron, R. (2013) Expanding the druggable space of the LSD1/CoREST epigenetic target: new potential binding regions for drug-like molecules, peptides, protein partners, and chromatin. PLoS Comput. Biol. 9, No. e1003158.

(33) Kalin, J. H., Wu, M., Gomez, A. V., Song, Y., Das, J., Hayward, D., Adejola, N., Wu, M., Panova, I., Chung, H. J., Kim, E., Roberts, H. J., Roberts, J. M., Prusevich, P., Jeliazkov, J. R., Burman, S. S. R., Fairall, L., Milano, C., Eroglu, A., Proby, C. M., Dinkova-Kostova, A. T., Hancock, W. W., Gray, J. J., Bradner, J. E., Valente, S., Mai, A., Anders, N. M., Rudek, M. A., Hu, Y., Ryu, B., Schwabe, J. W. R., Mattevi, A., Alani, R. M., and Cole, P. A. (2018) Targeting the CoREST complex with dual histone deacetylase and demethylase inhibitors. Nat. Commun. 9, 53.

(34) Milelli, A., Marchetti, C., Turrini, E., Catanzaro, E., Mazzone, R., Tomaselli, D., Fimognari, C., Tumiatti, V., and Minarini, A. (2018) Novel polyamine-based histone deacetylases-Lysine demethylase 1 dual binding inhibitors. Bioorg. Med. Chem. Lett. 28, 1001-1004.

(35) Pessina, A., Albella, B., Bayo, M., Bueren, J., Brantom, P., Casati, S., Croera, C., Gagliardi, G., Foti, P., Parchment, R., ParentMassin, D., Schoeters, G., Sibiril, Y., Van Den Heuvel, R., and Gribaldo, L. (2003) Application of the CFU-GM assay to predict acute drug-induced neutropenia: an international blind trial to validate a prediction model for the maximum tolerated dose (MTD) of myelosuppressive xenobiotics. Toxicol. Sci. 75, 355-367.

(36) Karmodiya, K., Krebs, A. R., Oulad-Abdelghani, M., Kimura, H., and Tora, L. (2012) H3K9 and H3K14 acetylation co-occur at many gene regulatory elements, while H3K14ac marks a subset of inactive inducible promoters in mouse embryonic stem cells. $B M C$ Genomics 13, 424.

(37) Löscher, W., Gillard, M., Sands, Z. A., Kaminski, R. M., and Klitgaard, H. (2016) Synaptic vesicle glycoprotein 2A ligands in the treatment of epilepsy and beyond. CNS Drugs 30, 1055-1077.

(38) Hunt, C. A., Schenker, L. J., and Kennedy, M. B. (1996) PSD95 is associated with the postsynaptic density and not with the presynaptic membrane at forebrain synapses. J. Neurosci. 16, 13801388.

(39) Falkenberg, T., Mohammed, A. K., Henriksson, B., Persson, H., Winblad, B., and Lindefors, N. (1992) Increased expression of brainderived neurotrophic factor mRNA in rat hippocampus is associated with improved spatial memory and enriched environment. Neurosci. Lett. 138, 153-156.

(40) Elmariah, S. B., Crumling, M. A., Parsons, T. D., and BaliceGordon, R. J. (2004) Postsynaptic TrkB-mediated signaling modulates excitatory and inhibitory neurotransmitter receptor clustering at hippocampal synapses. J. Neurosci. 24, 2380-2393.

(41) Sassoé-Pognetto, M., Utvik, J. K., Camoletto, P., Watanabe, M., Stephenson, F. A., Bredt, D. S., and Ottersen, O. P. (2003) Organization of postsynaptic density proteins and glutamate receptors in axodendritic and dendrodendritic synapses of the rat olfactory bulb. J. Comp. Neurol. 463, 237-248.

(42) Cooke, S. F., and Bliss, T. V. P. (2006) Plasticity in the human central nervous system. Brain 129, 1659-1673.

(43) Matsuzaki, M., Honkura, N., Ellis-Davies, G. C. R., and Kasai, H. (2004) Structural basis of long-term potentiation in single dendritic spines. Nature 429, 761-766.

(44) Oakley, H., Cole, S. L., Logan, S., Maus, E., Shao, P., Craft, J., Guillozet-Bongaarts, A., Ohno, M., Disterhoft, J., Van Eldik, L., Berry, R. and Vassar, R. (2006) Intraneuronal $\beta$-amyloid aggregates, neurodegeneration, and neuron loss in transgenic mice with five 
familial Alzheimer's disease mutations: Potential factors in amyloid plaque formation. J. Neurosci. 26, 10129-10140.

(45) Schroeder, F. A., Lewis, M. C., Fass, D. M., Wagner, F. F., Zhang, Y.-L., Hennig, K. M., Gale, J., Zhao, W.-N., Reis, S., Barker, D. D., Berry-Scott, E., Kim, S. W., Clore, E. L., Hooker, J. M., Holson, E. B., Haggarty, S. J., and Petryshen, T. L. (2013) A selective HDAC1/2 inhibitor modulates chromatin and gene expression in brain and alters mouse behavior in two mood-related tests. PLoS One 8 (8), No. e71323.

(46) Watson, P. J., Fairall, L., Santos, G. M., and Schwabe, J. W. R. (2012) Structure of HDAC3 bound to co-repressor and inositol tetraphosphate. Nature 481, 335-340.

(47) Millard, C. J., Watson, P. J., Celardo, I., Gordiyenko, Y., Cowley, S. M., Robinson, C. V., Fairall, L., and Schwabe, J. W. R. (2013) Class I HDACs share a common mechanism of regulation by inositol phosphates. Mol. Cell 51, 57-67.

(48) Guidance for Industry: Estimating the Maximum Safe Starting Dose in Initial Clinical Trials for Therapeutics in Adult Healthy Volunteers. U.S. Department of Health and Human Services, https:// w w w . f d a . g o v / d o w n lo a d s/D r u g s / GuidanceComplianceRegulatoryInformation/Guidances/ UCM078932.pdf.

(49) Hahne, H., Pachl, F., Ruprecht, B., Maier, S. K., Klaeger, S., Helm, D., Médard, G., Wilm, M., Lemeer, S., and Kuster, B. (2013) DMSO enhances electrospray response, boosting sensitivity of proteomic experiments. Nat. Methods 10, 989-991.

(50) Shevchenko, A., Wilm, M., Vorm, O., and Mann, M. (1996) Mass spectrometric sequencing of proteins from silver-stained polyacrylamide gels. Anal. Chem. 68, 850-858.

(51) Tyanova, S., Temu, T., and Cox, J. (2016) The MaxQuant computational platform for mass spectrometry-based shotgun proteomics. Nat. Protoc. 11, 2301-2319.

(52) Baumgartel, K., Green, A., Hornberger, D., Lapira, J., Rex, C., Wheeler, D. G., and Peters, M. (2018) PDE4D regulates spine plasticity and memory in the retrosplenial cortex. Sci. Rep. 8, 3895.

(53) Chen, L. Y., Rex, C. S., Casale, M. S., Gall, C. M., and Lynch, G. (2007) Changes in synaptic morphology accompany actin signaling during LTP. J. Neurosci. 27 (20), 5363-5372.

(54) Rex, C. S., Chen, L. Y., Sharma, A., Liu, J., Babayan, A. H., Gall, C. M., and Lynch, G. (2009) Different Rho GTPase-dependent signaling pathways initiate sequential steps in the consolidation of long-term potentiation. J. Cell Biol. 186, 85-97. 